\title{
INTERREGNO PARLAMENTARIO $Y$ ELECCIONES: EXCESOS Y DEFECTOS
}

\author{
POR \\ FERNANDO SANTAOLALLA LÓPEZ \\ Letrado de las Cortes Generales \\ Profesor de Derecho Constitucional. Universidad de Alcalá
}

\section{INTRODUCCIÓN}

La disolución de las Cortes Generales por el Real Decreto 100/2004, de 19 de enero, ha hecho reaparecer el mismo problema que en ocasiones precedentes: el del control o fiscalización del Gobierno tras la disolución de las cámaras, control que es virtualmente nulo, según una generalizada apreciación y tal como se demostrará más tarde.

A pesar de su importancia, este problema apenas suscita comentarios en los interregnos entre dos parlamentos, $y$, una vez iniciada la nueva legislatura, llega a desaparecer, como el Guadiana, a los ojos de los estudiosos y, lo que es más sorprendente, de sus presuntos perjudicados.

La cuestión no debería preocupar en exceso si ese periodo sin Parlamento (salvo la representación reducida que significa la Diputación Permanente) fuese breve. Sin embargo, no es así. Como se comprueba con la lectura del Decreto mencionado, la disolución o muerte civil del Congreso y el Senado se produce el mismo día de su publicación en el $\mathrm{BOE}$, o sea, el 20 de enero de 2004. La elección se dispone para el domingo 14 de marzo y la reunión constitutiva de las cámaras para el 2 de abril siguiente. De este modo, y sin perjuicio de su legalidad, transcurre 
un periodo de 72 días desde la disolución hasta que las cámaras pueden reunirse y comenzar el ejercicio de sus funciones. Si a lo anterior se añade que en el momento de la disolución, las Cortes llevaban 20 días fuera de periodos de sesiones (del 1 al 20 de enero) y, por tanto sin posibilidad de reunirse, al menos de modo regular, la conclusión es que así como el Gobierno se mantiene y actúa durante todo ese periodo de más de 90 días, lo contrario ocurre con la representación popular.

Curiosamente, en esta disolución de 2004 se han presentado temas y problemas de primera magnitud (como la guerra de Irak, el encuentro o pacto del consejero jefe del Gobierno catalán con miembros de una banda terrorista, las supuestas filtraciones de la anterior noticia desde instancias gubernamentales, la publicidad institucional juzgada de sesgada por la Junta Electoral Central, etcétera), que posiblemente reclamaban su debate y tratamiento en las cámaras. Ello demuestra que estos paréntesis entre distintas Cortes no son tan irrelevantes como parece desprenderse de la escasa atención que se les dedica.

La pregunta no es si esta situación resulta ajustada a la ley -que en una buena dosis puede responderse en términos afirmativos- sino si el régimen legal que tenemos es el apropiado. Lo que interesa es determinar si la regulación vigente de los interregnos parlamentarios está a la altura de la "sociedad democrática avanzada" de la que habla el preámbulo de nuestra Constitución. Mucho nos tememos que no, según se tratará de demostrar en las páginas siguientes. También resulta cuestionable si dentro del marco que ofrece la Constitución cabe encontrar una fórmula que mitigue al menos los problemas detectados, punto éste en el que cabe avanzar una respuesta positiva.

\section{EL INTERREGNO PARLAMENTARIO: ASPECTOS BÁSICOS}

Partimos de la consideración de que el equilibrio de poderes que representa el Parlamento respecto al Gobierno resulta, a pesar de todas sus insuficiencias y limitaciones, pieza esencial del Estado de Derecho. El enorme poder que acumula todo Gobierno conlleva un uso potencialmente abusivo. No es necesario traer a colación citas de autoridad, por tratarse de un principio generalmente aceptado. Por eso, en la medida que exista un Gobierno - lo que en la práctica equivale a un continuum apenas interrumpido- se requiere la presencia de ese contrapeso que aporta el Parlamento, especialmente mediante las iniciativas de los miembros y grupos de la oposición. No faltan casos en que esto no es posible, lo que habrá de aceptarse como irremediable. Sin embargo, el principio debe ser el inverso: allí donde no aparezca un 
obstáculo jurídico o político insuperable, debe buscarse el procedimiento que asegure la vigencia del Parlamento. El Derecho debe esforzarse por descubrir los mecanismos que, sin perjudicar a otros bienes constitucionales, aporten la fiscalización parlamentaria sin la que la tentación autoritaria puede ser insuperable.

Esto tiene perfecta aplicación a la cuestión que nos ocupa: el interregno parlamentario o espacio temporal que media entre dos parlamentos sucesivos. Dicho interregno constituye la muerte civil de la institución, su desaparición como órgano actuante. Y puede producirse bien por agotamiento de su mandato, o sea, por el transcurso del plazo para el que fue elegido, bien por su disolución anticipada.

Como decíamos, resulta inquietante que durante ese interregno el Gobierno pueda mantenerse como tal y sin la presencia del contrapoder que aporta la representación popular. Esta situación se produce precisamente entre nosotros, con la agravante de que el artículo 101 de la Constitución impone el cese del Gobierno y su transformación en Gobierno en funciones sólo "tras la celebración de elecciones". Por tanto, como luego se verá, al concluir la legislatura o disolverse las cámaras se abre un periodo con un Gobierno en plenitud de atribuciones pero sin Parlamento. Y cuando el primero se transforma en funciones tampoco, como veremos, existe medio fiable de controlar que actúa en consonancia con este carácter.

Lógicamente el Estado constitucional demanda alguna solución, total o parcial, a este problema. Como ha escrito Recoder de Casso, "desde la Revolución francesa el Parlamento se convierte en institución permanente que ha de existir siempre y de la que no cabe prescindir nunca del todo. Alguna solución debe, pues, arbitrarse para procurar esa presencia en aquellas funciones cuyo abandono, aunque sea temporal, pone en manos del Gobierno un poder excesivo y en aquellas otras sin cuyo ejercicio se perturbaría la funcionalidad del conjunto»².

Dos regulaciones se han combinado en España para alumbrar un resultado claramente insatisfactorio: por un lado, los paréntesis tan dilatados que impone el artículo 68.6 de la Constitución entre un Con-

1 Esta previsión del Gobierno en funciones ha sido desarrollada muy desafortunadamente por el artículo 21 de la Ley 50/1997, del Gobierno, según hemos denunciado en 2001 (a) p. 1575. Véase también ReVENGA, 1988, p. 66, Alvarez Conde," 1996-97, p. 191, Pérez Tremps, 1996-97, p.111, y FernándeZ-CARnicero, 2001, p. 241.

2 Véase, 2001, p. 1312-1317. No obstante, este autor realiza una interpretación a nuestro juicio excesivamente limitada de lo que pueden realizar las Diputaciones permanentes de las cámaras. 
greso y el siguiente, según se detalla más tarde; por otro, la práctica carencia de toda presencia parlamentaria durante ese tiempo, pues las Diputaciones permanentes están previstas taxativamente por el artículo 78 para unos supuestos extraordinarios y dejan desatendidas toda una serie de exigencias políticas.

Ambos artículos siguieron muy de cerca lo establecido en los artículos 53 y 62, respectivamente, de la Constitución republicana de 1931, como se comprueba con su simple cotejo. Mas dicha Constitución, tan innovadora en numerosos aspectos, se dejó arrastrar por la inercia decimonónica, y probablemente resultó desajustada para las necesidades de la época: el ejecutivo no era el poder todavía reducido de la centuria anterior $y$, por tanto, su vigilancia se hacia más apremiante; al tiempo, las dificultades para el traslado a la capital de los miembros del Parlamento habían desaparecido en buena parte, lo que permitía atender simultáneamente unas eventuales funciones del Congreso y la preparación de las nuevas elecciones. La institucionalización de la Diputación permanente no era más que un tributo histórico y resultaba muy cuestionable desde el punto de vista funcional ${ }^{3}$.

Si esto era así en el primer tercio del siglo pasado, con mucha mayor razón lo era a finales del mismo y comienzos del siglo XXI: el poder de los gobiernos ha crecido en extensión e intensidad y no representa la más mínima dificultad el concurrir a sesiones parlamentarias para aquellos diputados que estén interesados en su reelección.

\section{DURACIÓN Y CÓMPUTO DE LA LEGISLATURA}

La legislatura es el periodo de tiempo por el que se elige un Parlamento. Las constituciones suelen regular claramente este aspecto, pues es lo que permite asegurar la renovación periódica de la institución, para que así la misma responda a su misión democrática de reflejar las preferencias del electorado. Sin perjuicio de las cámaras que se renuevan por partes, lo normal es establecer legislaturas de cuatro, cinco y hasta seis años.

Existen en el Derecho comparado tres sistemas de cómputo de dicho plazo, basados en el dies a quo o día que se toma como referencia a estos efectos: a) la fecha de las elecciones; b) la fecha de proclama-

3 Pérez Serrano, por ejemplo, señalaba (1976, p. 763) que las cuestiones que plantea esta institución son complejas y graves, desde su composición interna hasta su eficacia. 
ción de los resultados o expedición de las credenciales electorales y c) la fecha de la sesión constitutiva o primera reunión del Parlamento elegido.

Según se desprende, directa o indirectamente, de la regulación constitucional, pertenecen al primer sistema países como Francia, Grecia e Italia. El artículo 121 del Código electoral francés dispone que "los poderes de la Asamblea Nacional expiran el tercer martes de junio del quinto año siguiente a la elección». El artículo 53 de la Constitución helénica dispone que "los diputados serán elegidos por cuatro años consecutivos desde el día de las elecciones generales». Por su parte, la Constitución italiana dispone primero (art. 60) que la Cámara de Diputados y el Senado se eligen por cinco años y añade después (art. 61) que "las elecciones a las nuevas cámaras se celebrarán dentro de los setenta días siguientes a la expiración de las anteriores».

Finlandia ha sido el único país entre los consultados que ha adoptado el segundo sistema, consistente en fijar como dies a quo la fecha de proclamación de los nuevos diputados electos. El artículo 3 de la Ley orgánica del Parlamento afirma que "el mandato de los diputados dará comienzo en cuanto fueren declarados electos». Curiosamente, al revés de los otros países, el dies ad quem no es el cumplimiento de los cuatro años siguientes a esa fecha, sino el día en que se celebren las siguientes elecciones.

Son más numerosos los países que han acogido el tercer sistema, donde el arranque de la legislatura se sitúa en la primera sesión del nuevo Parlamento. Esto se desprende del artículo 39 de la Ley Fundamental de Bonn, que dispone que el Bundestag o Asamblea Federal es elegido por cuatro años y que "su mandato expira al reunirse el nuevo Bundestag". Más claramente, el artículo 27 de la Ley constitucional austríaca afirma que "la legislatura del Nationalrat -o Consejo Nacional- durará cuatro años contados desde el día de su primera sesión". Por su parte, el artículo 156 de la Constitución portuguesa proclama que «el mandato de los diputados dará comienzo con la primera reunión de la Asamblea de la República después de las elecciones y cesará con la primera reunión de ésta después de las elecciones siguientes». Finalmente, el artículo 5 del capítulo tercero de la Ley sueca de 1994, por la que se reforma el Instrumento de Gobierno, señala que «la elección surtirá efecto durante el período comprendido entre la primera reunión del Parlamento recién elegido y la reunión del Parlamento siguiente que se elija. Dicho periodo constituirá la legislatura». 


\section{EL SISTEMA ESPAÑOL Y SU APLICACIÓN PRÁCTICA}

Sobre este particular, el artículo 68.4 de la Constitución española dispone:

«El Congreso es elegido por cuatro años. El mandato de los Diputados termina cuatro años después de la elección o el día de la disolución de la Cámara».

Lo mismo sienta el artículo 69.6 para el Senado.

A la vista de ambos artículos, no parece existir duda sobre la duración entre nosotros de la legislatura: variable, pero con una extensión máxima de cuatro años.

No resulta tan claro, en cambio, su comienzo. En todo caso, parece razonable aceptar como dies a quo el de las elecciones: el texto constitucional se refiere a "la elección", no a la constitución de la cámara o a una tercera circunstancia. De otra parte, la fijeza y simplicidad de esta fórmula la hace también preferible frente a una hipotética adopción de la proclamación del resultado electoral ${ }^{4}$ (cuya fecha puede ser variable a tenor de la LOREG ${ }^{5}$ ).

El dies ad quem, como se deduce de lo antes señalado, resulta variable en función del modo de finalización de la legislatura. Si «el mandato de los Diputados termina cuatro años después de la elección o el día de disolución de la Cámara", quiere decirse que puede deberse bien al transcurso de ese cuatrienio, bien a la disolución anticipada decretada por el presidente del Gobierno al amparo del artículo 115 (o a los otros casos de disolución).

La primera modalidad debía tener carácter general y la segunda resultar más bien ocasional. Y no sólo por aparecer mencionada en primer lugar, sino porque la misma conlleva una fijeza en el tiempo de los comicios y, por tanto, una mayor neutralidad: todos los contendientes electorales pueden prever con la misma certidumbre sus bazas y estrategia electoral. En la medida que extrema la igualdad de oportunidades de los candidatos, resulta la alternativa más democrática. En cambio, la segunda modalidad es susceptible de una instrumentación

${ }^{4}$ Esta interpretación la recogimos ya en la primera edición de nuestro Derecho parlamentario español. Véase de la misma obra, 1990, p. 91. Coinciden en la interpretación AlzAGA, 1978, p. 472 y CAZORLA, 1986, p. 332.

5 No hay que olvidar que, a tenor del artículo 108.4 de la LOREG, la proclamación de diputados y senadores electos puede variar en función de si se recurren o no las resoluciones de las juntas electorales provinciales ante la Junta Electoral Central. 
interesada en beneficio del Gobierno que la decreta o de su partido, como atestigua una amplia experiencia histórica ${ }^{6}$. Esto merma, o puede mermar, su impronta democrática.

En la práctica, todas las legislaturas han finalizado mediante disolución anticipada, por lo que permanece inédita la que en principio debía ser la solución ordinaria de agotamiento del periodo de cuatro años ${ }^{7}$. Esto también se ha producido en las legislaturas VI (1996-2000) y VII (2000-2004), a pesar de que en ambas había transcurrido prácticamente la mayor parte de ese cuatrienio y de que, consiguientemente podía haberse utilizado el procedimiento al efecto del artículo 43.2 de la LOREG (infra). Sin embargo, y mucho nos tememos que aquí reside parte de la explicación, esto último habría supuesto mantener el Parlamento hasta el término de la legislatura, con la consiguiente incomodidad para el Gobierno y beneficio para la oposición. Y como es el primero el que tiene la facultad de optar entre este término o la disolución, es obvio que no ha podido superar la tentación por lo segundo, que le reducía considerablemente el tiempo de hostigamiento y crítica.

Así, las cámaras elegidas para la VI legislatura lo fueron el 3 de marzo de 1996. Consiguientemente, para agotar dicho periodo tendrían que haber llegado hasta el mismo día del año 2000. Sin embargo, fueron disueltas por el Real Decreto 64/2000 con efectos del 18 de enero de 2000 , lo que supuso un "ahorro", en términos de vigilancia, para el Gobierno de un mes y medio. A su vez, las cámaras elegidas el 12 de marzo de 2000 para la VII legislatura habrían completado los cuatro años del mandato parlamentario en la misma fecha del año 2004. Sin embargo, han concluido con los mismos efectos que en el caso anterior, concretamente el 20 de enero de este año, por disponerlo así el Real Decreto 100/2004.

Esta circunstancia no se oculta en los mencionados decretos, que, como ya se ha dicho, se presentan como «de disolución del Congreso y

6 BAYÓn CHACÓn se refiere a la dolorosa experiencia de lo que había sido la disolución del Parlamento a través de nuestra historia constitucional. Véase de este autor, 1999, p. 243. También sobre esta cuestión véase BAR CENDón, 1989, p. 115, FERNÁNDEZ SEGADO, 1998, p. 153, SANTAOLALLA, 1990, p. 105 y 2001, p. 1751.

7 Véanse para la disolución de la constituyente el Real decreto 3073/1978, de 24 de diciembre (BOE de 1 de enero 1979); para la de la I legislatura, el Real Decreto 2057/1982, de 27 de agosto (BOE de 30 de agosto); para la de la II, el Real Decreto 794/1986, de 22 de abril; para la de la III el Real Decreto 1047/1989, de 1 de septiembre, (BOE 2 de septiembre); para la de la IV, el Real Decreto 534/1993, de 12 de abril, (BOE de 13 de abril); para la de la V, el 1/1996, de 8 de enero (BOE de 9 de enero); para la de la VI, el Real Decreto 64/2000, de 17 de enero (BOE de 18 de enero) y para la de la VII, el Real Decreto 100/2004, de 19 de enero (BOE de 20 de enero). 
del Senado y de convocatoria de elecciones", según reza su título. Y en su preámbulo se invoca el artículo 115 de la Constitución como fundamento de los mismos. Por tanto, es la segunda variante de conclusión de la legislatura la que se impone, la que en principio cabría calificar como anómala o excepcional.

Que el Gobierno se haya aprovechado de esta ventaja no deja de ser coherente con su particular posición, aunque desde luego no resulte encomiable desde el punto de vista institucional. Lo sorprendente es que los teóricos perjudicados por esta decisión no hayan hecho valer la alternativa que coincidía con sus intereses y con los institucionales. La oposición está llamada en un sistema democrático a apurar los mecanismos de control y a crear con sus denuncias la cultura de limitación y responsabilidad. Sin esto, es difícil que el sistema evolucione por sí mismo a cotas de mayor autenticidad.

Mas, ¿acaban aquí los problemas? Mucho nos tememos que no, que también la Constitución y la legislación de desarrollo aportan una regulación que en nada ayudan a la presencia vigilante del Parlamento a lo largo de toda la vida del Gobierno.

\section{LA RAÍZ DEL PROBLEMA: EL ARTÍCULO 68.6 DE LA CONSTITUCIÓN COMBINADO CON EL 78}

El artículo 68.6 de la Constitución, combinado con el 78, constituye parte del deficiente sistema de conclusión de la legislatura. Recordemos lo que establece el primero de estos artículos:

"Las elecciones tendrán lugar entre los treinta días y sesenta días desde la terminación del mandato. El Congreso electo deberá ser convocado dentro de los veinticinco días siguientes a la celebración de las elecciones".

De este modo, al forzar que las elecciones tengan lugar entre el trigésimo y el sexagésimo día posterior a la conclusión del mandato, se obliga a una solución no muy recomendable: la fecha de las elecciones, lejos de mantenerse la misma para las convocatorias sucesivas (por ejemplo, el 14 de marzo o el segundo domingo de marzo), debe variar en al menos 30 días de elección en elección. En el caso concreto de la VIII legislatura, esto habría significado que las elecciones no habrían podido tener lugar antes del 12 de abril de 2004, o sea, treinta días más tarde al menos de la expiración de la VII.

Este sistema comporta dos efectos negativos: por un lado, se pierde la objetividad y conocimiento seguro de la fecha de las elecciones para 
las cámaras, pues como decimos deberá ser al menos posterior en 30 días al de las elecciones anteriores; por otro, en caso de agotarse sucesivas legislaturas (que es en principio lo deseable) llegaría un momento en que habría que celebrar elecciones en periodos manifiestamente inconvenientes, como el estival y el navideño. De este modo, como el sistema no es muy funcional, no hay interés real en su aplicación. Falta así el acicate para que pueda formarse una idea sólida de la fecha en que normalmente deberían celebrarse las elecciones (por ejemplo, tal domingo de tal mes) y con ello la referencia segura para exigir al Gobierno el agotamiento real de la legislatura. Algo de esto ha podido influir en la ya relatada conclusión de las legislaturas VI y VII.

Pero lo peor de este sistema es que alarga innecesariamente el tiempo en que el Gobierno se encuentra sin fiscalización ni control. Es aquí donde aparece el no menos desafortunado artículo 78, pues la Diputación permanente como órgano de continuidad parlamentaria apenas brinda solución a estos requerimientos. Dado lo establecido en dicho artículo y la interpretación que se ha impuesto en la práctica, sólo en dos casos concretos y no muy corrientes puede controlar la actuación del Gobierno: convalidación de decretos leyes y situaciones del artículo 116 de la Constitución ${ }^{8}$. Cualquier otro suceso impide la reunión de la Diputación permanente. La referencia a "velar por los poderes de las Cámaras cuando éstas no estén reunidas" es de discutible aplicación a la situación comentada y, sobre todo, de un alcance que tiene todo excepto precisión.

Es verdad que se han construido meritorias interpretaciones para salir de situación tan cuestionable y es verdad que, en casos extraordinarios como los considerados ${ }^{9}$, habría que recurrir a las mismas. Sin

${ }^{8}$ Sólo en un caso -y a petición propia- compareció un ministro para informar a la Diputación Permanente. Se trató de la comparecencia del ministro de Defensa para informar de hechos que habían dado lugar a la detención de tres jefes militares (operación Galaxia), tramitada al amparo del artículo 203 del Reglamento del Congreso y celebrada el 11 de octubre de 1982. Posteriormente, todas las solicitudes de convocatoria de la Diputación permanente fueron inadmitidas por su mesa a lo largo de las legislaturas II, V, VI y VII.

9 RECODER (2001, p. 1316) considera que, por su carácter extraordinario, las Diputaciones permanentes también podrían conocer de la inhabilitación del rey (art. 59.2) y de la coerción autonómica en el caso de la del Senado (art. 155). Estos mismos criterios son asumidos por PÉREZ DoBóN, 1984, p. 32.

ALONSO DE ANTONIO (1992, p. 168) añade a las anteriores la autorización de la declaración de guerra del artículo 63.3 y la formulación de preguntas e interpelaciones y solicitudes de comparecencia. Por su parte, LAVILLA (1998, p. 753) defiende que bajo "velar por los poderes de las cámaras" caen las iniciativas del propio Gobierno y 
embargo, la cicatería del artículo 78 (seguramente nada inocente) no ofrece seguridad al respecto. Y, sobre todo, deja sin protección situaciones que sin llegar a esos casos límite bien pueden merecer el escrutinio de los representantes populares.

\section{DESARROLLO DEL ARTÍCULO 68.6 POR LA LOREG}

Volviendo a lo dispuesto en el artículo 68.6, no puede extrañar que el deseo de regularizar la duración de las legislaturas y convocar las elecciones para las mismas fechas haya forzado a recurrir al mecanismo alternativo y teóricamente excepcional de la disolución anticipada. Pues anticipar la muerte civil del Parlamento es el único medio de cuadrar las cuentas, esto es, que puedan celebrarse las elecciones entre el trigésimo y el sexagésimo días posteriores a la terminación del mandato - según reclama tan desafortunado precepto-coincidiendo con el transcurso de cuatro años desde los anteriores comicios.

Hay que señalar que el artículo 69 no impone solución semejante para el Senado. Consiguientemente, los plazos podrían haber sido más breves. Sin embargo, la suerte del Congreso ha arrastrado al Senado: al hacerse coincidir la fecha de elección para ambas asambleas por puras razones de oportunidad, los plazos del artículo 68.6 han acabado aplicándose al Senado.

Desgraciadamente, los males no acaban en lo indicado, pues la LOREG se ha encargado de agrandar el roto jurídico del artículo 68.6 de la Constitución. El artículo 43 de la misma, en su actual versión, dispone lo siguiente:

"1. En los supuestos de elecciones a Cortes Generales o de Asambleas Legislativas de las Comunidades Autónomas en las que el Presidente del Gobierno o los respectivos Presidentes de los Ejecutivos autonómicos hagan uso de su facultad de disolución anticipada expresamente prevista en el ordenamiento jurídico, los decretos de convocatoria se publican, al día siguiente de su expedición, en el "Boletín Oficial del Estado", o, en su caso, en el "Boletín Oficial» de la Comunidad Autónoma corres-

acontecimientos extraordinarios que no llega a precisar. Además admite unas atribuciones implícitas de las Diputaciones permanentes que las habilitarían para situaciones de máxima gravedad, como las antes señaladas y otras parecidas, como el nombramiento de la Regencia, disolución de entes locales, etcétera. Nosotros mismos (1990, p. 193) hemos defendido la aplicabilidad de los instrumentos de información (preguntas, interpelaciones), por no constituir función parlamentaria de control en sentido estricto. En parecido sentido se manifiesta BAR CENDóN, 1989, p. 259. 
pondiente. Entran en vigor el mismo día de su publicación. Los decretos de convocatoria señalan la fecha de las elecciones que habrán de celebrarse el día quincuagésimo cuarto posterior a la convocatoria.

2. En los supuestos de elecciones a Cortes Generales o de Asambleas Legislativas de las Comunidades Autónomas en las que el Presidente del Gobierno o los respectivos Presidentes de los Ejecutivos autonómicos no hagan uso de su facultad de disolución anticipada expresamente prevista en el ordenamiento jurídico, los decretos de convocatoria se expiden el día vigésimo quinto anterior a la expiración del mandato de las respectivas Cámaras, y se publican al día siguiente en el Boletín Oficial del Estado» o, en su caso, en el "Boletín Oficial» de la Comunidad Autónoma correspondiente. Entran en vigor el mismo día de su publicación. Los decretos de convocatoria señalan la fecha de las elecciones que habrán de celebrarse el día quincuagésimo cuarto posterior a la convocatoria.»

Como puede verse, se antepone la regulación (ap.1) de la disolución anticipada a la de (ap. 2) agotamiento de la legislatura. Este dato y el tono empleado reflejan perfectamente la realidad: lo primero es el supuesto normal y lo segundo lo ocasional. Justo lo contrario de lo que teóricamente cabe defender y, a veces, se defiende en la práctica.

Por otro lado, este artículo impone que las elecciones deberán celebrarse el quincuagésimo cuarto día posterior a la convocatoria, por tanto ni un día antes ni un día después. De este modo, el Gobierno, tan favorecido por otros artículos, carece de todo margen de apreciación en este punto concreto. Pero lo más censurable es que, en vez de intentar acortar el periodo sin Cortes Generales, lo extiende hacia el máximo permitido, ya que el quincuagésimo cuarto día está más cerca del sexagésimo que del trigésimo. Queremos decir, desde la perspectiva que venimos defendiendo, que interesaría cumplir con el mínimo que demanda la Constitución —el plazo de 30 días- para que así el Parlamento pudiese funcionar cuanto antes.

Ahora bien, el deslizamiento hacia el plazo máximo de 60 días deriva, ciertamente, de otras estipulaciones de la LOREG que serán comentadas más adelante.

La regulación constitucional y legal que hasta aquí hemos resumido no ayuda precisamente a la vigencia de uno de los principios fundamentales del Estado de Derecho, como es que el Gobierno esté en la mayor medida posible vigilado y contrapesado por el Parlamento. Si, como bien dice Cazorla $^{10}$, el tiempo es un elemento fundamental del fenómeno electoral, puede afirmarse que la regulación comentada manipula este fenómeno en un sentido no precisamente democrático.

10 Véase, 1986, p. 327. 
Que la solución escogida no es muy razonable se deduce, sin ir más lejos, de nuestros antecedentes históricos. Así, al amparo de la Ley electoral de 18 de marzo de 1846, se disolvieron las Cortes el 31 de octubre de ese año, se celebraron elecciones el 6 de diciembre -por tanto a los 36 días de la disolución-y se convocaron las cámaras para el 25 de diciembre - esto es, a los 55 días de aquella fecha-. De modo parecido, por decreto de 6 de diciembre de 1868 se convocaron elecciones, que además eran constituyentes, para los días 15 a 18 de enero de 1869 - o sea, entre los 40 y los 43 días-, de tal modo que las Cortes pudiesen reunirse el siguiente 11 de febrero - lo que equivale a 65 días desde la disolución- ${ }^{11}$. Como se ve, los plazos son más breves que los actualmente existentes: si se suman los 54 días para la celebración de las elecciones con los 25 que permite el artículo 68.6 de la Constitución, se bordean los 80 días hasta la primera reunión de las Cortes Generales.

A la misma conclusión se llega a partir de las regulaciones existentes en otros países de nuestro entorno, a las que a continuación se hace referencia.

\section{MOMENTO DE LA CELEBRACIÓN DE ELECCIONES}

La fecha de celebración de elecciones está deficientemente regulada, al menos a los efectos que nos ocupan, si se compara con las soluciones implantadas en otros países europeos. Son numerosos los Parlamentos que se eligen más tempranamente, con lo que se favorece la más pronta reunión de la nueva cámara o cámaras.

En concreto, algunos países obligan a celebrar las elecciones antes de que expire la legislatura, solución que parece óptima desde la perspectiva de asegurar el control parlamentario del poder ejecutivo. Según el artículo 39 de la Ley Fundamental alemana, las elecciones para la Asamblea federal (Bundestag) se celebran en el último trimestre de la legislatura. Más preciso todavía, el artículo 27.2 de la Constitución austríaca dispone que el Gobierno debe convocar las elecciones de tal modo que el Consejo Nacional pueda reunirse el día siguiente al de la expiración del cuarto año de la legislatura. En el caso de Francia, la Constitución (art. 12) sólo regula el supuesto de disolución de la Asamblea Nacional, previendo que las elecciones sucesivas tengan lugar entre los 20 y los 40 días siguientes. El supuesto de agotamiento de la legislatura está, en cambio, regulado en el Código electoral, que impo-

11 Fuente de los datos anteriores: Fernández Domínguez, 1992, p. 91 y 120. 
ne (art. 122) que las nuevas elecciones se celebren dentro de los 60 días que preceden a aquel momento. La Constitución portuguesa es poco explícita, pero al menos su artículo 176.1 admite como posible que la fecha de las elecciones sea anterior a la de expiración de la legislatura.

En un segundo grupo nos encontramos a los países que obligan a celebrar las elecciones en el momento en que fenece la actual legislatura. Por tanto, no se anticipan las elecciones, pero tampoco se retrasan con relación a ese momento. En Bélgica, de no mediar disolución, las elecciones se celebran el cuarto domingo del mes de mayo (arts. $105 \mathrm{y}$ 239 del Código electoral), por tanto coincidiendo con el fin del mandato. De mediar disolución, las subsiguientes elecciones deben tener lugar dentro de los 40 días posteriores (art. 46 de la Constitución). En Finlandia, las elecciones deben celebrarse cada cuatro años, coincidiendo con la expiración de la legislatura (art. 3 de la Ley orgánica del Parlamento).

Finalmente, están los países en que las elecciones deben realizarse después de la conclusión del mandato de las cámaras. Son minoría los parlamentos que se acogen a esta solución. Por ejemplo, el artículo 61 de la Constitución italiana prevé un plazo muy amplio, como los 70 días siguientes a la terminación de las anteriores cámaras (o sea, cinco años después de su elección). Pero, al menos, la legislación electoral (art. 4 del decreto legislativo 20 de diciembre 1993, no 533 y art. 11.3 del decreto presidencial 30 marzo $1957 \mathrm{n} .{ }^{\circ}$ 361) rebaja esta exigencia, al disponer que los decretos de convocatoria de las elecciones deben publicarse en la Gazzetta Ufficiale 45 días antes de la fecha de los comicios como mínimo. En todo caso, el inconveniente que se deriva de ese periodo tan amplio se amortigua por la prorogatio de las cámaras, que será comentada más tarde.

También Grecia se acoge a este sistema, pues (art. 53 de la Constitución) las nuevas elecciones se deben celebrar en un plazo de 30 días desde la conclusión de la anterior asamblea.

El caso más llamativo es el del Parlamento británico. De acuerdo con el calendario que figura como anexo de la Representation of the People Act 1985, las elecciones para la Cámara de los Comunes tienen lugar el decimoséptimo día posterior del real decreto de convocatoria (Royal Proclamation) ${ }^{12}$, por tanto, en un tiempo mínimo.

Si se hace balance comparativo de nuestra regulación constitucional - las elecciones deben tener lugar entre los treinta y los sesenta días desde la terminación del mandato- con lo observado en otros países

12 Fuente: The Electoral Comission, 2003, p. 8. No obstante, en su informe esta comisión aconseja incrementar el plazo general hasta los 25 días. 
europeos, la conclusión no puede ser más negativa para la primera: frente a la solución más practicada de adelantar las elecciones respecto al término del mandato parlamentario, para así asegurar la continuidad parlamentaria, se pospone a un momento muy posterior; y frente a los países que también siguen esto último, el plazo es mayor en comparación con Grecia y, sobre todo, en comparación con el Reino Unido, mientras que, en comparación con Italia, carecemos del mecanismo de la prorogatio de las cámaras, que permite su intervención, de sentirse su necesidad.

\section{SITUACIÓN DEL PARLAMENTO TRAS LA CONCLUSIÓN DE LA LEGISLATURA O SU DISOLUCIÓN}

En los países de Europa occidental que hemos consultado no se contempla una fórmula como la de la Diputación permanente española para cuando concluye la legislatura o se disuelven las cámaras por disposición del Gobierno. Al contrario, rigen otras que favorecen mucho más la presencia y actuación de la representación popular ${ }^{13}$. El común denominador consiste en el mantenimiento del Parlamento, bien hasta la reunión del nuevo, con lo cual no se produce solución de continuidad en este órgano, bien hasta la celebración de elecciones, con lo que el periodo sin cámaras se reduce al más bien breve que media entre ese momento y la constitución de las nuevas.

Como ya se recogió, el Bundestag alemán tiene una legislatura de cuatro años y "su mandato expira al reunirse el nuevo Bundestag" (art. 39 de la Ley Fundamental). Por tanto, la vida de una cámara concluye con el nacimiento de la siguiente, sin solución de continuidad.

Muy parecido es lo que establece la Constitución austríaca (art. 27), pues el mandato del Consejo Nacional no expira hasta que se reúna el nuevo Consejo.

La Segunda Cámara de los Países Bajos -equivalente a nuestro Congreso- puede ser disuelta, pero en este caso la disolución surte efecto el día que se reúna la cámara recién elegida (art. 64.3 de la Ley Fundamental).

Por su parte, el mandato de los diputados de la Asamblea de la República portuguesa cesa con la primera reunión de ésta después de las elecciones (art. 156.1 de la Constitución).

13 Una buena introducción a este aspecto, tan poco tratado, se encuentra en LAVILLA 1998, p. 689. 
Finalmente, la elección del Riksdag sueco surte efecto durante el período comprendido entre la primera reunión del Parlamento recién elegido y la reunión del Riksdag siguiente que se elija (capítulo $3 .^{\circ}$, artículo 5 del Instrumento de Gobierno). Todos estos países, en definitiva, extienden el mandato parlamentario en modo tal que no pueda existir paréntesis en el órgano de representación popular.

Otros países, sin llegar a este punto, aseguran la continuidad de la cámara extinta hasta la celebración de las nuevas elecciones. Si a esto se añade que el período entre ese momento y la primera reunión del nuevo Parlamento es más bien corto, se podrá comprobar que no es mucho el tiempo en que el país permanece sin un Parlamento operativo. Así, en Bélgica el mandato de los diputados y de los senadores de elección directa se extiende hasta la fecha fijada para las elecciones o, como concreta el artículo 239 del Código electoral al remitirse al 105, hasta la reunión ordinaria (cuarto domingo de mayo) de los colegios electorales llamados a elegir a los sustitutos de los anteriores. Y en Finlandia el mandato de sus diputados da comienzo en cuanto fueren declarados electos y expira en el momento en que se celebren las elecciones siguientes (art. 3 de la Ley orgánica del Parlamento).

Si se comparan estas regulaciones con la española vigente, la conclusión es bastante adversa para esta última. Mientras que en los países citados se favorece en extremo la vigencia del Parlamento hasta empalmar con el siguiente, en las Cortes Generales se abre un hiato que puede llegar acercarse a los tres meses, sin otra presencia parlamentaria que la más teórica que efectiva de la Diputación permanente.

\section{ESPECIAL REFERENCIA A LA SOLUCIÓN IMPERANTE EN ITALIA}

Especial referencia merece la solución italiana, en cuanto, hasta cierto punto, pudo haber inspirado la del artículo 68.6 de la Constitución española. El artículo 61 de la Constitución italiana de 1947 establece un plazo amplio, como es el de 70 días para la celebración de elecciones desde la disolución, más otros 20 días para la primera reunión de las nuevas cámaras.

La diferencia capital con nuestro sistema viene dada por la ausencia de un órgano como la Diputación permanente $y$, en cambio, por la presencia de la figura de la prorogatio: según el apartado dos del artículo mencionado, "quedarán prorrogados los poderes de las cámaras precedentes mientras no se reunieren las nuevas». Digamos de entrada 
que se diferencia entre esta situación de prorogatio (en virtud de la cual el titular de un órgano cesado continúa ejercitando las funciones del órgano correspondiente hasta la toma de posesión del sucesor) y la situación de prórroga, relativa a la prolongación de la vida de un órgano más allá de su vida normal.

Morhoff saludó muy positivamente el nuevo sistema que representaba este artículo 61 por venir a superar los inconvenientes del sistema anterior, en el cual, tras la disolución de las cámaras, el poder ejecutivo quedaba sustraído a todo control por el legislativo ${ }^{14}$.

La verdad es que no ha resultado pacífica la definición del significado de la prorogatio. Siguiendo a Mazzoni Honorati ${ }^{15}$, podemos decir que existen tres posturas fundamentales. Por un lado, un grupo minoritario (Balladore Pallieri, Giocoli Nacci, Di Ciolo) defiende una interpretación amplia, según la cual las cámaras mantendrían durante esta fase la plenitud de sus poderes ${ }^{16}$. Por otro, un grupo también minoritario (Mortati) que postula lo opuesto, o sea, una consideración restrictiva, en cuya virtud el Parlamento se tendría que confinar a los asuntos corrientes o de ordinaria administración. Entre medias se encuentra la postura que más nos interesa, en cuanto profesada por un sector mayoritario (Elia, Paladin, A.A. Romano y la propia Mazzoni), que entiende que las cámaras pueden ejercitar sus funciones en circunstancias de necesidad y de urgencia o para la ejecución de actos debidos. Se citan como tales la convalidación de decretos leyes, la deliberación sobre el estado de guerra, la aprobación de la ley de prórroga y de la ley de presupuestos generales del Estado. También se podrían debatir las leyes devueltas por el presidente de la República en ejercicio de su veto suspensivo y la acusación del Jefe del Estado siempre que medie urgencia.

En la práctica, desde 1972 las cámaras prorrogadas se han reunido en diversas ocasiones para actos como los mencionados. Además, mediando consenso de todos los grupos se ha llegado a aprobar algunas leyes durante ese período (como en 1996 las relativas a violencia sexual y sobre el delito de usura). Se mantuvieron también actividades de control y vigilancia, como las reuniones de la comisión sobre los servicios de información y seguridad y la comisión de los servicios radiotelevisivos. En cuanto a los instrumentos de inspección, se han admitido excepcionalmente preguntas de respuesta oral, mientras las preguntas de respuesta escrita han sido consideradas admisibles siem-

14 Véase, 1948, p. 57.

15 Véase de esta autora, 1999, p. 77.

${ }^{16}$ Esta parece ser también la postura de Morhoff en cuanto se refiere al mantenimiento de los poderes legislativos y de control del Parlamento. 
pre en el Senado y con carácter oscilante en la Cámara de Diputados. Por supuesto, ninguna limitación rige para los actos de relevancia interna, como la aprobación del presupuesto de las cámaras, y para la autorización para procesar a un parlamentario.

La conclusión que se extrae del sistema italiano es que, sin alcanzar la solución óptima, ofrece una base mínima para que el Parlamento pueda desplegar sus funciones parlamentarias durante el interregno parlamentario.

\section{EXCESIVA DURACIÓN DEL PERÍODO PREELECTORAL}

Si recapitulamos todo lo que hemos venido comentando, se confirma que el artículo 68.6 de la Constitución posibilita un plazo muy dilatado entre Parlamento y Parlamento, plazo que el artículo 42 de la LOREG, lejos de atemperar, potencia en extremo.

Veamos ahora cómo se descompone todo el proceso de 54 días que media entre la convocatoria y los comicios, en modo a juzgar si existe alguna fase o elemento que pudiese ser eliminado o recortado. En aras de la claridad, nos referiremos sólo a los trámites que tienen relevancia a efectos de este estudio.

Siempre contando a partir de la fecha de la convocatoria de elecciones, antes del noveno día posterior deben designarse los representantes de los partidos, federaciones y coaliciones ante la Junta Electoral Central (art. 168.1). Antes del décimo deben comunicarse los pactos de coaliciones (art. 44.1). Las candidaturas deben presentarse entre el decimoquinto y el vigésimo días posteriores (art. 45). El vigésimo segundo día deben publicarse las candidaturas así presentadas (art. 47.1). Dos días después, o sea, el vigésimo cuarto día, las juntas electorales provinciales comunican a los representantes las irregularidades apreciadas de oficio o denunciadas por otros representantes. Durante los días vigésimo quinto y vigésimo sexto pueden subsanarse estas irregularidades (art. 47.2). En la jornada siguiente, o sea, el vigésimo séptimo día las juntas electorales provinciales realizan la proclamación de las candidaturas (art. 47.3), las cuales se publican en el BOE el vigésimo octavo día posterior (arts. 47.5 y 169.4). Durante los dos días siguientes (o sea, el vigésimo noveno y el trigésimo) se puede presentar recurso contra la proclamación ante el Juzgado contencioso administrativo por parte de los candidatos excluidos y de los representantes de las candidaturas proclamadas o denegadas (art. 49.1). Este recurso debe resolverse dentro de los dos días siguientes (esto es, hasta el trigésimo se- 
gundo desde la convocatoria, art. 49.3). Contra la sentencia así dictada cabe recurso de amparo ante el Tribunal Constitucional a interponer entre el trigésimo tercero y trigésimo cuarto días (art. 49.4). El Tribunal Constitucional debe resolverlo no más tarde del trigésimo séptimo día (art. 49.4). Se inicia entonces la campaña electoral de quince días (art. 51), que alcanza así hasta el quincuagésimo segundo día. El quincuagésimo tercero día constituye la llamada jornada de reflexión, sin propaganda electoral (art. 53) ${ }^{17}$. Y así, finalmente, se llega al quincuagésimo cuarto día, el de celebración de las elecciones.

Como puede apreciarse, se trata de un procedimiento bastante complejo, que, entre otros inconvenientes, tiene el de prolongar excesivamente el periodo sin Parlamento.

Se ha querido garantizar una serie de intereses, básicamente los de los candidatos, con una actitud en principio plausible. Pero el problema surge por haberse llevado esta tutela hasta el extremo, con la consecuencia de haberse olvidado, también hasta el extremo, lo esencial de la democracia, como es que el Gobierno esté vigilado y controlado por el Parlamento. Pues todo ese garantismo de la LOREG se traduce en un innecesario alargamiento de los plazos para la elección y constitución de las nuevas cámaras, aspecto éste que debía de haber gozado de atención prioritaria. Como escribió Morhoff, constituye una aspiración democrática el que no haya solución de continuidad entre la cámara que muere y la que nace ${ }^{18}$. ción.

Veamos ahora algunos de los aspectos más críticos de esa regula-

\section{LOS TRES CONTROLES SOBRE LAS CANDIDATURAS}

A nuestro juicio, uno de los inconvenientes mayores del calendario electoral es la sucesión de tres instancias revisoras de las candidaturas presentadas, en tan corto espacio de tiempo como el que media entre el vigésimo segundo y vigésimo noveno días. En efecto, primero cabe la reclamación ante la junta electoral provincial previa a la proclamación de candidatos; luego, tras la proclamación, cabe recurso ante el Juzgado de lo contencioso administrativo y, finalmente, contra su resolución, cabe recurso de amparo electoral ante el Tribunal Constitu-

17 Para un estudio pormenorizado de estos artículos véase CAZORLA PriEto, 1986 passim.

18 Morhoff hace este comentario al estudiar el artículo 61 de la Constitución italiana. Véase, 1948, p. 56. 
cional. Nótese que la primera, o sea, la Junta Electoral Provincial se compone de tres magistrados y dos catedráticos o profesores titulares de Derecho, ciencia política o sociología. Por tanto, aunque no es un órgano propiamente judicial, tiene una composición que hace presumir su imparcialidad y profesionalidad. Especial importancia tiene el hecho de que la mayoría de sus miembros pertenece a la carrera judicial. En el mismo sentido, el artículo 16.1 de la LOREG garantiza su inamovilidad, dotando a todos de un status cuasi judicial ${ }^{19}$. Si a esto se añade el trámite de corrección de irregularidades, no cabe temer que se produzcan errores graves en la proclamación de las candidaturas. Por eso, estimamos que se comprenden poco las dos instancias sucesivas, especialmente la segunda, la que se produce ante el Tribunal Constitucio$\mathrm{nal}^{20}$. En ambas, se produce a la postre lo mismo: la revisión de la regularidad de las candidaturas proclamadas o excluidas.

No se diga que el Tribunal Constitucional revisa la cuestión desde la perspectiva de los derechos fundamentales, como el del artículo 23.2 de la Constitución, pues aunque esto es verdad (pero no toda la verdad: no pocas veces revisa cuestiones de legalidad ordinaria ${ }^{21}$ ) resulta manifiestamente insuficiente para justificar esta dilatación del proceso electoral, con el precio ya visto: la existencia de un Gobierno insuficientemente vigilado. La consideración de los derechos fundamentales, y entre ellos el de sufragio pasivo, resulta obligada para todos los órganos que intervienen en el proceso electoral, según impone el tantas ve-

${ }^{19}$ En parecido sentido, Serena Velloso (1986, p. 93) otorga a la Administración electoral las siguientes notas: ser autónoma y soberana en su ámbito, no ser órgano judicial, administrativo o legislativo y ser organización compleja. Por su parte, SolozÁBAL ECHEVARRÍA (1997, p. 40) califica a la Administración electoral como organización neutral y a la Junta Electoral Central de órgano independiente y judicializado, si bien sigue siendo Administración. ARNALDo AlcubILLA (1997, p. 370) subraya como caracteres de esta Administración el ser independiente, netamente judicializada, especializada, no permanente con excepción de la Junta Electoral Central y jerárquica. También Rallo Lombarte, 1997, p. 231 y Gálvez MuÑOz, 1999, p. 97.

20 BAStida FreIJEDo (1986, p. 48) comparte en alguna medida nuestro juicio, pues si bien admite plenamente el recurso contencioso administrativo, que debería ser ante el Tribunal Superior de Justicia correspondiente, rechaza de plano cualquier otro posterior, incluido el de amparo. Por su parte, PULIDO QUECEDo recomienda (1992, p. 448) residenciar todo el control de las candidaturas en el seno del poder judicial. También ARNALDO (1997, p. 383) califica de perturbadora a la revisión última en vía de amparo por el Tribunal Constitucional. Finalmente, GARCía SORIANo (2002, p. 302) reconoce que con las medidas jurisdiccionales incluidas en la LOREG se garantizaría suficientemente el derecho a la tutela judicial efectiva, aunque no se previese el recurso de amparo ante el Tribunal Constitucional.

${ }^{21}$ Como, por ejemplo, ocurre con las STC 103/1996, 46/1997 y 26/2003. 
ces citado artículo 5.1 de la LOPJ ${ }^{22}$, y, por tanto, este aspecto debe entenderse cubierto por el recurso contencioso administrativo. Si tanto se insiste en el recurso de amparo ante el Tribunal Constitucional habrá de convenirse que dicho artículo ha fracasado.

Por otro lado, este control triple constituye una opción por lo cuantitativo, en lugar de lo cualitativo, opción más propia de una democracia primeriza e insegura que de una madura y realista. Estimamos que en éste como en otros campos no importa tanto el número de garantías, como el que las que existan - aunque sean pocas- funcionen debidamente. La existencia de tres instancias se cuestiona por sí mis$\mathrm{ma}$, desde el momento en que las posteriores parecen poner en duda el resultado útil de las anteriores ${ }^{23}$. Y lo más importante: estas garantías a la postre se quedan en bien poco, como lo revela el que los afectados disponen de unos plazos de una fugacidad inaudita para recurrir $y$, sobre todo, que lo mismo se produce con los órganos llamados a resolver, lo que hace presumir que unos y otros se verán privados del sosiego apropiado para la toma juiciosa de decisiones ${ }^{24}$.

Por ello, acaso resultaría más sensato dejar como única garantía la que proporciona la Junta Electoral Central resolviendo recursos contra los acuerdos de las juntas electorales provinciales (art. 21), introduciendo a cambio unos plazos más realistas. Lo anterior podría completarse con la judicialización integral de la Administración electoral, o sea, con la composición exclusiva por jueces y magistrados, que reforzaría la independencia de todas las juntas. Recuérdese, además, que dichas juntas pueden consultar y ser instruidas por la Junta Electoral Central con alcance vinculante (art. $19.1 \mathrm{c}$, d y f), por lo que cualquier duda puede encontrar solución uniforme en todas las circunscripciones ${ }^{25}$.

En definitiva, una única garantía bien organizada valdría más que tres tan ligeras. Por lo demás, no cabe olvidar la vigencia del control judicial sobre la validez de las actas y credenciales de los parlamentarios (art. 70.2 de la Constitución y 109-120 de la LOREG), a través del lla-

${ }^{22}$ La STC 68/1987 reconoce que el objeto de estas impugnaciones no es más que los defectos o irregularidades que presenten las candidaturas electorales, y no se extiende a otros ámbitos.

${ }^{23}$ En concreto Figueruelo BurRieza (1989, p. 136) denuncia un cierto fraude amparista, esto es, el uso desproporcionado del recurso de amparo.

${ }^{24}$ Así, García SoRIANo no deja de reconocer que el plazo para dictar sentencia por el juzgado de lo contencioso es "de imposible cumplimiento práctico". Véase de esta autora, 2000, p. 257.

25 ARnaldo Alcubilla (2002, p. 133) defiende que sea la Junta Electoral Central la que resuelva las demandas y afirma que la judicialización ha de ser siempre un último recurso. 
mado recurso contencioso electoral en sentido estricto. Esto puede permitir la corrección de las posibles irregularidades e, incluso, la anulación de la elección si se detectan vicios graves a lo largo de todo el proceso electoral ${ }^{26}$. Esto se reconoció en la STC 149/2000, que se comenta acto seguido.

La STC 149/2000, aunque declaró inconstitucional y nulo el artículo 21.2 de la LOREG en la parte que excluía el control judicial de las resoluciones en alzada de las juntas electorales, dejó al margen de esta condena "las actuaciones de los mencionados órganos de la Administración electoral que se integran plenamente en el procedimiento electoral, del que constituyen meras fases o momentos". De estas últimas, añadió, no es exigible que resulten sometidas a un control judicial autónomo o independiente ${ }^{27}$. Con ello, el Tribunal Constitucional venía a asumir la dificultad de integrar en el proceso electoral las normales garantías judiciales, confirmando así lo que venimos defendiendo, esto es, que no se puede llegar a una regulación del proceso electoral que perjudique su principal objetivo: dotar al país de una pronta representación parlamentaria ${ }^{28}$.

A pesar de la coincidencia, pensamos que esta sentencia adolece de un exceso de formalismo, como reconoce el voto particular del magistrado Garrido Falla. Este pronunciamiento ${ }^{29}$ ignora que diversos acuer-

${ }^{26}$ Así lo defiende Fernández Segado, 1994, p. 67. Véase también Entrena Cuesta, 1997, p. 475 y PARdo FALCón, 1999, p. 159.

27 Según García Soriano (1996, p. 78) el control judicial quedaría así reservado para los siguientes actos: a) resoluciones de las juntas electorales sobre decisiones de los órganos de administración de los medios de radio y televisión de titularidad pública que afecten al pluralismo; b) actos de las juntas electorales de ejercicio de la potestad disciplinaria e imposición de multas; c) resoluciones sobre actos de campaña y de propaganda institucional en período electoral y d) distribución de emplazamientos para la colocación de carteles y propaganda.

${ }^{28}$ Cienco SielRa (2001, p. 95) critica esta sentencia por razones opuestas a las nuestras: dejar al margen de la declaración de inconstitucionalidad actos de trámite electoral merecedores del control judicial. No obstante admite que los plazos fugaces son incompatibles con lo propio de los recursos, y que puede resultar problemático recurrir aisladamente los actos preparatorios o de trámite vinculados al procedimiento electoral.

${ }^{29}$ Lo que el Tribunal Constitucional condena son «aquellos actos y disposiciones, emanados en ejercicio de las competencias que asigna a dichas Juntas el artículo 19 LOREG, que no están directamente vinculados con el desarrollo del procedimiento electoral y que, por ello, son susceptibles de fiscalización judicial con carácter inmediato y a través del oportuno recurso contencioso-administrativo común. La exclusión absoluta respecto de ellos de toda posibilidad de interponer cualquier clase de recurso judicial que establece el art. 21.2 LOREG aparece manifiestamente contraria al derecho fundamental a la tutela judicial efectiva que consagra el art. 24.1 CE.» 
dos de las juntas electorales, incluso no incardinados en el proceso electoral, se avienen mal con su control por la jurisdicción contenciosa administrativa. La doble instancia que proporciona el artículo 21 de la LOREG debía servir de garantía de su corrección y legalidad. De hecho, una sentencia anterior -la 197/1988- admitió que el ordenamiento jurídico pueda disponer que determinada actuación pública se controle, sin ulterior recurso jurisdiccional, por órganos a los que se les atribuye la única función de velar por el respeto objetivo de la legalidad, como eran precisamente las juntas electorales.

Por lo demás, la improcedencia del recurso de amparo en esta materia será comentada en el epígrafe 16 , a donde nos remitimos.

\section{POSIBLES OBJECIONES A UN CONTROL SIMPLIFICADO DE LAS CANDIDATURAS}

Nuestra postura topará probablemente con la objeción de que hace caso omiso de lo previsto en el artículo 106 de la Constitución, en el sentido de que toda actividad administrativa debe estar sometida al control judicial. Algunos aducirán que es imprescindible que toda la actividad desarrollada por las juntas electorales esté sometida a su revisión por los tribunales.

Esta posible objeción es claro exponente de la pandemia hiperformalista que invade nuestro mundo jurídico y contra la que, vista su persistencia, no parece haberse descubierto antídoto eficaz ${ }^{30}$. Este virus ha conducido a una interpretación de los preceptos constitucionales tan literal que raya en lo pedestre. Pues ¿puede alguien afirmar con fundamento que cuando los constituyentes aprobaron el artículo 106.1 tenían en mente a unos órganos tan atípicos como las juntas electorales? ¿Puede objetivamente sostenerse que éstas forman parte del supuesto contemplado? A nuestro juicio, ese precepto está pensado para la Administración ordinaria - central, autonómica y local- pero no para algo tan especial e irregular como es la Administración electoral, cuyo carácter administrativo se matiza profundamente por el Tribunal Constitucional. En concreto la STC 197/1988, si bien defiende la condición de órganos administrativos de las juntas electorales y rechaza que constituyan órganos jurisdiccionales, afirma que «es cierto que la composi-

30 Esta situación es reconocida por Figueruelo (1991, p. 109) quien habla del «extremado celo tutelador que obedece a la voluntad política de conseguir la credibilidad del procedimiento electoral». Por su parte, Fernández SEgAdo (1993 p. 61) reconoce una actitud hipergarantista por parte del constituyente en esta materia. 
ción de las Juntas está fuertemente judicializada y que todos sus miembros son inamovibles durante los períodos para los que son elegidos, sin que guarden relación alguna de dependencia con la Administración y que, en su funcionamiento, están protegidos por una serie de garantías tendentes a asegurar su imparcialidad y objetividad en el cumplimiento de la misión que la Ley les encomienda de asegurar la transparencia y objetividad del proceso electoral y del principio de igualdad".

Convéngase que lo que describe el Tribunal Constitucional en poco se parece a lo que solemos denominar Administración pública y que, por tanto, mal se haría sujetando lo descrito a lo previsto para ésta, al menos como principio general.

La ley, en este caso la ley electoral, puede perfectamente limitar el contenido y alcance de los derechos fundamentales, como ya proclamó el artículo 4 de la Declaración de derechos del hombre y del ciudadano de 1789 («estos límites - a la libertad- no pueden ser determinados más que por ley"). Lo que debe hacer la ley en su delimitación de las libertades, como sabiamente dice el artículo 53.1 de nuestra Constitución, es respetar su contenido esencial. Aplicado esto al caso que nos ocupa, no parece exagerado afirmar que el contenido esencial del derecho a la tutela judicial no resulta perjudicado por la exclusión del control judicial ordinario de un porcentaje absolutamente ínfimo de actos administrativos - los propios de la Administración electoral frente a los procedentes de las Administraciones públicas en sentido amplio-, cuando además median razones de peso y existen otros medidas que garantizan sobradamente la imparcialidad y corrección de dichos actos ${ }^{31}$.

Por eso, constituye un extremismo interpretativo el demandar que todos los actos, sin excepción, de cualquier órgano que total o parcialmente tenga carácter administrativo tenga que someterse al normal control judicial. Es el fiat ius pereat mundus una vez más.

Acaso, como excepción a lo que venimos defendiendo, podría mantenerse el recurso contencioso administrativo ante la Sala especial del artículo 61 de la LOPJ en el supuesto a que se refieren los artículos 44.4 y 49.5 de la LOREG (prohibición de presentar candidaturas a agrupaciones de electores relacionadas con partidos políticos disueltos o suspendidos). Pues refiriéndose estos últimos artículos a partidos políticos

31 Como reconoce García SoRIANo (1996, p. 83), el recurso contencioso ordinario sería inoperante para los actos incluidos en el procedimiento electoral. En ese caso, ¿es garantía real un recurso contencioso especial con unos plazos imposibles por su fugacidad? ¿Interesa recargar — todavía más- a los órganos juridiccionales con cuestiones que posiblemente no tienen la trascendencia de otras? 
relacionados con bandas terroristas es de temer que las juntas electorales provinciales o inferiores no puedan sustraerse a la presión de estas bandas y acaben, consiguientemente, admitiendo candidaturas en contra de la prohibición legal ${ }^{32}$. En todo caso, el recurso de amparo debe quedar excluido.

Confirma nuestra impresión el Derecho comparado. A continuación veremos el caso de cuatro países cuyo carácter constitucional nadie pondría en duda. Pues bien, en ninguno de ellos se establece algo que recuerde ni de lejos lo que ocurre en el nuestro. Seguramente esta enorme diferencia se produce porque las reglas electorales en estos países tienen como finalidad principal proteger al electorado y no tanto al candidato ${ }^{33}$, que es lo que parece correcto en un orden valorativo.

Así, en el Reino Unido, según consta en los artículos 107-137 de la Representation of the people Act 1949, todas las reclamaciones electorales se presentan directamente ante un mismo tribunal: la División del Banco de la Reina del Tribunal Supremo (High Court in the Queen's Bench Division). Se juzgan por dos jueces designados por dicho tribunal. Además, frente a nuestro sistema existen otras notorias diferencias: los plazos son diversos y más largos, según la entidad del ilícito que se denuncia $y$, por otro, la impugnación no suspende el desarrollo del proceso electoral, sin perjuicio de la repetición de la elección si fuese declarada nula. La decisión de los jueces causa firmeza y se comunica con efectos finales a la Cámara de los Comunes $^{34}$. Sin duda, esto es lo que permite un calendario tan expeditivo como el ya referido de diecisiete días.

En Italia se mantiene (art. 66 de la Constitución) el sistema clásico de verificación de actas por las propias cámaras al comienzo de la legislatura. El único control preelectoral previsto es el que se realiza por la Oficina Central Nacional (Ufficio centrale nazionale) sobre los acuerdos de cada oficina central de circunscripción (Ufficio centrale circoscrizionale $)^{35}$. Según los artículos 22 y 23 del DPR de 30 marzo 1957 no 361 , son las segundas las que efectúan la proclamación de candidatos, con facultades para introducir correcciones y anulaciones de las candi-

${ }^{32}$ Este comentario corresponde a la experiencia proporcionada por las elecciones locales de mayo de 2003. Véase la STC 85/2003, de 8 de mayo.

33 Así lo afirma para Francia García Soriano, 1997, p. 132.

34 Véase al respecto MAY, 1997, p. 35-37.

35 Lo que sí ha de reconocerse es que estos órganos están integrados exclusivamente por magistrados, designados por los tribunales del ámbito respectivo: vide arts. 12 y 13 del DPR de 30 marzo, 1957, n. ${ }^{\circ} 361$. 
daturas que no se adecuen a los requisitos legales. Dentro de la cuarenta y ocho horas siguientes, los delegados de las candidaturas pueden recurrir contra las eliminaciones de listas o de candidatos. $Y$, dentro de los dos días siguientes, resuelve la Oficina Central Nacional. Aquí acaba el procedimiento. Como se ve, sólo se produce un control revisor y éste ni siquiera posee la naturaleza de un proceso judicial, a pesar de la composición judicial de los órganos de la Administración electoral.

Por su parte, en Francia sólo existe como control de la proclamación de candidatos el que ejerce el tribunal administrativo correspondiente a requerimiento del prefecto. Según el artículo L157 del Código electoral, las candidaturas deben presentarse ante el prefecto veintiún días antes de la elección. Si el prefecto observa algún incumplimiento de los requisitos formales atinentes a las candidaturas, -él y sólo él- lo traslada en las veinticuatro horas siguientes al tribunal administrativo, el cual resuelve en los tres días siguientes (art. L159). Contra la decisión de este último sólo puede recurrirse ante el Consejo Constitucional competente para juzgar de la elección. Por tanto, sólo existe un control, bien que en este caso se haya optado por su judizialización. Lo cual no obsta una eventual impugnación del resultado electoral por cualquier elector de la circunscripción correspondiente ante el citado Consejo Constitucional, durante los diez días siguientes a su proclamación (art. L180), impugnación que, por lo demás, no constituye ejercicio de un derecho privado, sino acción realizada en interés público ${ }^{36}$. Pero esto forma parte de otro proceso posterior y distinto, como es el contencioso electoral $^{37}$.

Más claro, si cabe, es el caso de Alemania. Según los artículos 25-28 de la Ley electoral federal $(B W G)^{38}$, el Director electoral del distrito (Kreiswahlleiter) comprueba las candidaturas individuales tras su presentación. Si encuentra algún error, lo comunica al representante de la candidatura para que proceda a su rectificación. Acto seguido, y no más tarde del noveno día tras la conclusión del plazo para la presentación de candidaturas, la Comisión electoral del distrito (Kreiswahlausschuss) aprueba las candidaturas electorales, pudiendo rechazar las que no cumplan con los requisitos correspondientes. En este último caso, cabe recurrir dentro de los tres días siguientes ante la Comisión electoral del Land (Landeswahlausschuss), la cual debe resolverse en los tres días siguientes. Proceso semejante se desarrolla con las candidaturas de listas

36 Así lo afirma MASCLET, 1992, p. 104.

37 Sobre esta materia puede consultarse GARcía SoRIANO, 1999, p. 93.

38 Fuente: www.bundeswahlleiter.de. En dicho portal se encuentra tanto la ley electoral como el reglamento de desarrollo (Bundeswahlordnung-BWO). 
en los Länder ${ }^{39}$, si bien aquí es la Comisión electoral del Land la llamada a aprobarlas, pudiendo recurrirse su posible inadmisión ante la Comisión electoral federal (Bundeswahlausschuss). Sólo la candidatura rechazada y las autoridades electorales pueden interponer el recurso. Aquí cabe todo el contencioso. Como se ve, todos los controles operan dentro de la Administración electoral y para nada se prevé una posible acción ante los tribunales de justicia.

A mayor abundamiento, debe hacerse constar que estos órganos electorales ni siquiera tienen una parcial composición judicial, como ocurre entre nosotros, por lo que su garantía teórica es menor. Así, según el artículo 9 de la BWG, el Director electoral federal y su adjunto son nombrados por el Ministro federal del Interior, los Directores electorales de Land y de distrito lo son por los gobiernos territoriales o la agencia designada por éstos. Finalmente, los miembros de las comisiones son nombrados por esos directores, que también actúan como sus presidentes.

A la vista de los datos anteriores, si se considera que las garantías electorales que nos permitimos en España son necesarias para la protección del derecho del sufragio y la limpieza de las elecciones, habrá de convenirse que países como Reino Unido, Francia, Italia y Alemania no pueden ser calificados como verdaderos Estados de Derecho, pues están muy lejos de alcanzar esos niveles. Pero, como esta conclusión es ridícula, la sospecha se torna del otro lado, en el sentido de que nuestro país ha incurrido en un derroche de garantías, innecesarias y contraproducentes: ¡todo se protege en extremo... excepto el propio Parlamento!

\section{DURACIÓN DE LA CAMPAÑA ELECTORAL}

La duración de quince días de la campaña electoral (art. 51.2 de la LOREG) resulta excesiva, y eso que ya fue acortada desde los veinte iniciales por la Ley orgánica 13/1994, de reforma de la LOREG. En la práctica, esos quince días se ven precedidos por un largo periodo de intensa propaganda, la llamada precampaña, que se abre, cuando menos, con la convocatoria electoral. Tan es así que las diferencias entre esa precampaña y la campaña propiamente dicha se reducen a dos: la colocación de carteles y pancartas en postes y farolas y, sobre todo, la utilización gratuita de espacios de propaganda en las emisoras de radio y

39 Así lo advierten Boettcher y HögneR, 1994, p. 140. 
televisión de titularidad pública, aspectos de escasa incidencia en el resultado electoral ${ }^{40}$.

El plazo de quince días se ha convertido en un puro nominalismo, ya que, como decimos, cuando de verdad empieza la campaña es con la convocatoria de las elecciones, si no antes ${ }^{41}$. Esto se ha visto favorecido por la interpretación de la Junta Electoral Central (así acuerdo de 4 de noviembre de $1985^{42}$ ), en el sentido de que no está prohibido antes de la campaña oficial todo lo que no contenga expresa petición de voto, pues se trataría de algo protegido por la libertad de expresión.

Nuestra opinión es que está de más, bien la regulación del artículo 51.2 , bien esta interpretación. Esto último porque viene a dejar en nada la limitación de dicho artículo. De hecho, esta interpretación es otro exponente del formalismo desbocado que denunciábamos más arriba. Como cualquier técnico en publicidad sabe, se puede estimular la venta de un producto o servicio sin requerir expresamente su compra a los destinatarios del mensaje. Incluso podría resultar torpe y escasamente efectivo actuar de este modo. Lo más normal es mover su voluntad a través de procedimientos indirectos, más sutiles ${ }^{43}$. Pues bien, esto es lo que ocurre en el mercado electoral: no hace falta reclamar "vote al partido X" para que el efecto buscado - mover a los ciudadanos a votar a favor de una candidatura determinada- se pueda producir. Mil y una técnicas se utilizan de hecho con este fin. Es esto, en definitiva, lo que ha borrado prácticamente toda diferencia entre el plazo oficial de campaña y el período anterior, como cualquier observador puede testimoniar.

Por eso, para mantener la coherencia con un plazo semejante, la legislación francesa (art. 52.1 del Código electoral) prohibe todo acto de propaganda electoral en la prensa y medios audiovisuales durante los tres meses anteriores a la fecha de comienzo del mes en que se debe celebrar una elección. Y la ley 90-55 de 15 de enero de 1990 ha dispuesto el carácter permanente de esta prohibición para los medios audiovisuales ${ }^{44}$.

40 Así lo reconocen, al menos para la publicidad gratuita, WERT (1994, p. 97) y ARNALDO AlCUBiLla (2002, p. 140)

${ }^{41}$ Así lo reconoce también Santolaya Machetti (1995, p. 95 y 1997, p. 456), que califica de inoperante la actual prohibición de la precampaña. En igual sentido ARNALDO AlCUBiLla (2002, p. 137).

42 Fuente: Arnaldo Alcubilla y Delgado-Iribarren, 2003, p. 336.

${ }^{43}$ WERT, por ejemplo, tras quejarse (1994, p. 90) del formalismo de la LOREG en este punto, añade que un mensaje publicitario no tiene por qué ser menos eficaz si está elíptico. También reconoce que no existe diferencia entre la precampaña y la campaña oficial.

${ }^{44}$ Fuente: Adda, Couvert y Dufresnoy, 1995, p. 60. 
Como nada de esto existe en España, y dados los antecedentes comentados, la campaña electoral se extiende en realidad entre nosotros a lo largo de cincuenta y dos días, los que median entre la convocatoria y las cero horas del día inmediatamente anterior a la votación (art. 51.3 de la LOREG), plazo a todas luces desmesurado ${ }^{45}$.

Por eso, y sin perjuicio de otras reformas más profundas que podrían arbitrarse, creemos que nada grave ocurriría, sino todo lo contrario, si la campaña oficial se redujese a siete días. De este modo, se ahorraría un tiempo apreciable en aras del objetivo aquí defendido: cerrar cuanto antes el interregno parlamentario.

Mucho más interés para el desarrollo democrático de las elecciones tendría, en lugar de un plazo tan extenso como el actual, el conseguir la organización de debates televisivos entre los candidatos de los partidos principales, punto éste en el que sin duda caben diversas fórmulas. Como ha escrito Solozábal, "la idea de campaña electoral en un sistema democrático ... se adecúa mucho más al esquema del debate que al de la propaganda ${ }^{46}$. En definitiva, se trataría de optar más por lo cualitativo que por lo cuantitativo.

Otra alternativa sería mantener la duración de la campaña oficial y adelantar su comienzo. Esto es, en vez de producirse éste el trigésimo octavo día posterior la convocatoria podría hacerse a partir del trigésimo, por poner un ejemplo. Esto supondría que la campaña arrancaría después de haber resuelto las juntas electorales provinciales las reclamaciones contra las candidaturas, por tanto, con una presunción de corrección de las mismas. Una posible objeción a esta propuesta en el sentido de tener que agotarse necesariamente todas las instancias revisoras de las candidaturas, podría tener algún fundamento si se tratase de elecciones uninominales, donde puede ser crucial la presencia o ausencia de un determinado candidato. Mas, en el nuestro, en el que la votación es en circunscripciones plurinominales y por sistema de lista, apenas se comprendería esta crítica: el hecho de votarse fundamentalmente por listas de partidos o coaliciones de partidos aleja hasta el infinito de lo improbable que se vaya a presentar esa hipótesis, esto es, que a la postre vayan a variar los partidos que concurren como candidatos a las elecciones ${ }^{47}$.

${ }^{45}$ De todas formas, Francia padece el mismo problema que nosotros: el de la publicidad salvaje, practicada a despecho de lo que disponen las normas legales sobre lugares y plazos. Véase al respecto VINCENT y VILLIERS, 1993, p. 72. Esto viene a demostrar la ingenuidad de acotar formalmente estos periodos.

46 Véase de este autor, 1997. p. 44. También GonZaLO, 1997. p. 319.

47 Por lo demás, recordemos que hemos abogado por la supresión de al menos el recurso de amparo ante el Tribunal Constitucional. Sobre estas cuestiones puede verse BASSOLS, 1999, p. 51. 
Finalmente, otra alternativa, adaptada enteramente a la realidad, sería admitir que la convocatoria electoral determina la apertura de la campaña, por lo que podría prescindirse de un plazo específico para ésta. Incluso aunque se aceptase el aligeramiento de plazos que venimos defendiendo, la duración total del proceso electoral es suficientemente amplia como para que las candidaturas dispongan de tiempo suficiente para trasladar sus propuestas y mensajes al electorado. Nada sufrirían éstas desde esta perspectiva. A lo sumo, y si se insistiese en otra regulación también muy dudosa, como son los espacios de propaganda gratuita en la radio y televisión públicas, podría reservarse un periodo de siete a diez días a estos efectos.

\section{PLAZO Y CALENDARIO PARA LA CONSTITUCIÓN DEL PARLAMENTO}

Debemos considerar ahora el plazo que media entre la elección y la sesión constitutiva del nuevo Parlamento, que es lo que suele determinar el comienzo efectivo de sus funciones constitucionales.

En Alemania (art. 39 de la Ley Fundamental), en Irlanda (art. 16.3 de la Constitución) y en Grecia (art. 53 de la Constitución) se establece un plazo de 30 días a estos efectos. Por consiguiente, la primera sesión del nuevo Parlamento debe celebrarse antes del transcurso de un mes desde su elección.

Más exigentes son las constituciones de Suecia (art. 5 del capítulo $\left.3 .{ }^{\circ}\right)$, que dispone que ese acto tiene lugar el decimoquinto día posterior a las elecciones, pero no antes del cuarto desde la proclamación de los resultados, y de Dinamarca (art. 35), que prevé que la sesión constitutiva se celebre el duodécimo día hábil siguiente a la elección. También aquí debe incluirse a la Asamblea Nacional francesa: para el caso de disolución, la Constitución (art. 12) prevé su primera reunión el segundo jueves siguiente a su elección. Suponiendo que la misma tenga lugar en domingo, esto arroja un término de once días. Si la elección procede del agotamiento del mandato parlamentario, parece deducirse del Código electoral (art. 121 y 122) que la sesión inicial se produce al inicio del período de sesiones de abril, coincidiendo con la expiración de la asamblea anterior.

Por su parte, las cámaras italianas deben constituirse no más tarde del vigésimo día posterior a su elección (art. 61 de la Constitución).

La Constitución española (art. 68.6 in fine) afirma que "el Congreso electo deberá ser convocado dentro de los veinticinco días siguientes a 
la celebración de las elecciones". Nada se establece para el Senado, pero el acompasamiento de mandatos y el calendario electoral instaurados en la práctica han determinado la sujeción a la misma regla. Como fácilmente se comprueba, este apartado es el único en el que la regulación establecida no desmerece en comparación con los modelos foráneos. Por un lado, el plazo de veinticinco días no es muy distinto al de otros parlamentos. Por otro, no necesita agotarse, como claramente se deduce de la expresión "... dentro de los veinticinco días siguientes...». Así, el reciente Real Decreto 100/2004 ha previsto tan sólo diecinueve días entre la elección (14 de marzo) y la constitución del Congreso y el Senado (2 de abril).

Por su parte, la LOREG no se refiere directamente a este plazo. En cambio, lo predetermina con la regulación de los distintos incidentes que pueden mediar entre la elección y la proclamación de diputados y senadores electos por las juntas electorales, siendo esto último lo que permite que esos nuevos parlamentarios acudan a la sesión constitutiva en la fecha marcada en el decreto de convocatoria. Según nuestros cálculos, el calendario básico es el siguiente:

- en el mismo día de las elecciones, cada mesa electoral hace públicos los resultados y entrega la documentación correspondiente al juzgado de primera instancia y a la Junta Electoral Provincial (arts. 95 a 101);

- el 3. ${ }^{\circ}$ día posterior se produce el escrutinio general en cada provincia (art. 103.1), si bien puede suspenderse este acto un día adicional (art. 104.2) e incluso prolongarse hasta el $6^{\circ}$ día posterior al de la elección (art. 107.2);

- el 7. ${ }^{\circ}$ día los representantes de las candidaturas pueden presentar reclamaciones y protestas contra el acta del escrutinio (art. 108.2);

- el 8. ${ }^{\circ}$ día la Junta Electoral Provincial debe resolver sobre estas reclamaciones (art. 108.3);

- el 9. día cabe un nuevo recurso contra su resolución que se presenta ante la misma Junta;

- el $10 .^{\circ}$ día dicha Junta remite el recurso con un informe suyo a la Junta Electoral Central (art. 108.3);

- el 11. ${ }^{\circ}$ día la Junta Electoral Central emplaza a los representantes de las candidaturas para comparecer (art. 108.3);

- los $12 .^{\circ}$ y $13 .^{\circ}$ días se da audiencia a los representantes de las candidaturas; 
- el $14 .^{\circ}$ día la Junta Electoral Central resuelve el recurso y da traslado de la resolución a las juntas electorales provinciales para que efectúen la proclamación de electos (art. 108.3);

- finalmente, el $15 .^{\circ}$ día la Junta Electoral Provincial procede a la proclamación de electos (art. 108.4).

Como se ve, la duración es de tan sólo quince días y aun puede ser menor en el caso de que no se consuman algunos de los plazos. Desde luego en este cómputo no tomamos en cuenta los incidentes - nada baladíes, por cierto- de los recursos contencioso electorales y recursos de amparo, ya que los mismos no obstan a la constitución de las cámaras. A ellos nos referiremos más tarde.

Sí que interesa dejar constancia, para valorar la oportunidad de esos trámites ulteriores, de que en el calendario poselectoral se produce dos controles que, en principio, debían asegurar la corrección del resultado electoral: primero, el que efectúan las juntas electorales provinciales sobre las reclamaciones relativas a las actas de las mesas electorales y de escrutinio de las propias juntas, $y$, segundo, el que se produce acto seguido ante la Junta Electoral Central.

En Francia, el procedimiento está mucho menos formalizado. Sin perjuicio del control propio de la Comisión nacional de cuentas y financiación electoral (art. 52-14 del Código electoral), tan sólo se prevé (art. 85.1L) la existencia de una comisión de control de las operaciones de voto, compuesta por dos magistrados y un funcionario secretario designado por el prefecto. Su cometido se limita a emitir un informe que se remite al prefecto junto a las actas de recuento de voto. No parece, pues, que tenga capacidad para modificar por sí misma los resultados o proclamación de electos. Cualquier otra reclamación deberá considerarse en el contencioso electoral, que será referido más abajo.

También menos formalista es el proceso electoral en Alemania. A tenor de los artículos 70 a 81 del Reglamento federal electoral (Bundeswahlordnung-BWO), los distintos niveles de la Administración electoral informan a sus superiores sobre el resultado en el ámbito correspondiente. No está prevista reclamación o recurso alguno contra sus acuerdos por parte de los candidatos o sus representantes, si bien en ocasiones los órganos superiores pueden introducir correcciones en las cifras electorales. Al final, el Director electoral del distrito, el Director electoral del Land y el Director electoral federal proclaman los resultados del ámbito respectivo. Si aprecian un vicio de invalidez de la elección, deben impugnarla conforme al procedimiento que se refiere más tarde. 
Finalmente, en Italia, según se desprende del artículo 76 y siguientes del DPR de 30 marzo 1957 n. ${ }^{\circ} 361$, la Oficina central de circunscripción decide sobre la asignación de votos a la vista de las reclamaciones presentadas junto a las actas electorales de las mesas. Fuera de lo anterior, le está expresamente prohibido considerar o pronunciarse sobre cualquier extremo (art. 79). Es también esta oficina la que realiza la proclamación de electos en las circunscripciones uninominales y, tras el cómputo general hecho por la Oficina central nacional, la proclamación de los elegidos en las plurinominales. De modo terminante se añade que sólo a la Cámara de Diputados corresponde la convalidación de las elecciones y de sus componentes y que, en consecuencia, sólo ella se pronuncia sobre las impugnaciones, protestas y reclamaciones presentadas en los distintos órganos electorales (art. 87).

Si se compara lo que acaba de recogerse con el doble control de nuestro procedimiento electoral, se advierte que el mismo mal que antes denunciábamos -exceso de garantismo - reaparece aquí. Bien es verdad que en este caso no se traduce en una dilatación de los plazos para la constitución de las cámaras, pero sí en una complicación innecesaria que hace dudar de la calidad de estos controles. Pues, ¿en qué condiciones pueden resolver una reclamación las juntas electorales, provinciales y central, cuando sólo disponen de un día? Nos preguntamos si no sería preferible un solo control por la Administración electoral que redundaría en unas mejores condiciones para el órgano llamado a realizarlo.

\section{EL CONTENCIOSO ELECTORAL}

No acaban aquí las complicaciones. Pues, tras la proclamación del resultado electoral, cabe su impugnación a través del llamado contencioso electoral, el eventual recurso de aclaración y, finalmente, el recurso de amparo ante el Tribunal Constitucional.

A efectos de comprobar la corrección de este sistema, si sobra o falta algo, no estará de más echar un vistazo a lo establecido en otros países.

En el Reino Unido, como ya se expuso en el epígrafe 12, las reclamaciones electorales competen exclusivamente a la División del Banco de la Reina del Tribunal Supremo (High Court in the Queen's Bench Division), el cual decide con carácter definitivo e informa a la Cámara de los Comunes a los efectos correspondientes. No existe otro control.

En Francia, todas las reclamaciones relativas a la validez de las elecciones son competencia del Consejo Constitucional, por disponer- 
lo así el artículo 59 de su Constitución. En concordancia con lo previsto en los artículos 32 y siguientes de la Ordenanza n. 58 de 7 de noviembre de 1958, los artículos 179 y siguientes del Código electoral establecen lo que en apretada síntesis recogemos: el Ministro de Interior comunica a la Asamblea Nacional el nombre de las personas elegidas. Durante los diez días siguientes a la proclamación del resultado electoral cualquier elector inscrito en las listas electorales de la correspondiente circunscripción y los que presentaron su candidatura en la misma pueden presentar una reclamación por escrito. El Consejo Constitucional puede declararla inadmisible de no cumplir con los requisitos establecidos o no poder influir en el resultado electoral. Si se admite, se traslada al Diputado cuya elección se ve afectada para que formule las observaciones que tenga por procedentes. El Consejo puede, si lo estima procedente realizar pruebas y averiguaciones. Finalmente, decide por resolución motivada, pudiendo anular la elección impugnada o reformar la proclamación hecha por la comisión de recuento y proclamar al candidato que fue regularmente elegido.

En resumen, por disponerlo la Constitución hay un control de validez de las elecciones por el órgano de justicia constitucional. Pero, este control es único, no existe otro ni, en concreto, uno a cargo de los tribunales.

En Alemania, el control de la validez de las elecciones está a cargo de la propia Asamblea Federal (Bundestag), si bien contra su decisión cabe recurso ante el Tribunal Constitucional (art. 41 de la Ley Fundamental de Bonn). La Ley de verificación electoral (Wahlprüfungsgesetz-WPrG) disciplina el procedimiento: una comisión interna del Bundestag estudia las reclamaciones presentadas contra la validez de las elecciones y emite una propuesta al respecto, sobre la que finalmente decide la cámara. Contra esta resolución puede apelarse ante el Tribunal Constitucional. Pero obsérvese que ello es debido a la previsión expresa del artículo 41 de la Constitución. Además, esta apelación no está prevista como una manifestación más del recurso de amparo ante esta institución (Verfassungsbeschwerde), sino como un procedimiento autónomo, según se deduce de los artículos 13, 48 y 90 de la Ley del Tribunal Constitucional Federal (Gesetz über das Bundesverfassungsgericht), que regulan como dos competencias distintas el control de la validez de las elecciones, por un lado, y el recurso de amparo, por otro.

Finalmente, en Italia se mantiene como único control de la validez de las elecciones el que desarrollan las propias cámaras al comienzo de la legislatura. Según el artículo 66 de la Constitución "cada cámara se pronunciará sobre la validez de las actas de elección de sus miem- 
bros». Un reglamento interno de cada cámara (el Regolamento della Giunta delle elezioni) regula el procedimiento. En síntesis, toda persona con un interés personal, directo y cualificado en la elección puede presentar un recurso contra la proclamación de un diputado o senador. Dentro de la citada Junta de las elecciones se designa un ponente que estudia las reclamaciones. Tras la deliberación correspondiente en el seno de la Junta, la misma somete una propuesta a la cámara de anulación o convalidación de la elección contestada.

Mucho más complejo es el procedimiento de control de las elecciones en España. Como es sabido, los artículos 109 a 120 de la LOREG disciplinan el recurso contencioso electoral. Nada puede objetarse, pues, además de aportar un indispensable control imparcial, resulta consecuencia obligada de lo dispuesto en el artículo 70.2 de la Constitución ("La validez de las actas y credenciales de los miembros de ambas cámaras estará sometida al control judicial, en los términos que establezca la ley electoral»).

En cambio, nos merece muchas dudas, de oportunidad y constitucionalidad, el recurso de amparo ante el Tribunal Constitucional. Por un lado, dobla el control previsto en la Constitución, prolongando todavía más las consecuencias temporales de las elecciones. Su superfluidad se constata al reparar en los serios filtros que ya de por sí ha experimentado la proclamación de electos: unas primeras reclamaciones son resueltas directamente por las juntas electorales provinciales (art. 108.2) y otras segundas por la Junta Electoral Central (art. 108.3). Como estos dos órganos gozan de unas reconocidas condiciones de independencia, cabe presumir que la proclamación de electos y del resultado electoral será conforme a la legalidad.

Por si fuese poco lo anterior, es posible impugnar esas decisiones mediante un recurso contencioso electoral, no precisamente falto de garantías: la legitimación al efecto es amplia (entre otros cualquier candidato proclamado o no proclamado) y resulta obligada la intervención del ministerio público. Se prevé la audiencia de las partes afectadas, el recibimiento a prueba y la práctica de pruebas. Pero, sin duda, lo más significativo es que el competente para resolver dicho recurso es la Sala tercera del Tribunal Supremo ${ }^{48}$. Finalmente, por si existiese alguna oscuridad en la sentencia de esta última, es posible interponer un recurso de aclaración ante la misma.

${ }^{48}$ En el caso - aquí examinado- de las elecciones al Congreso y Senado, así como en las del Parlamento Europeo. En las elecciones autonómicas y locales el tribunal competente es la Sala de lo Contencioso del Tribunal Superior de Justicia de la correspondiente Comunidad Autónoma. 


\section{EL RECURSO DE AMPARO}

Pues bien, tras todo ese proceso creemos que debería darse por descontada la corrección jurídica de la solución finalmente adoptada. Siendo esto así, no se comprende qué aporta un segundo control, como es el que representa el recurso de amparo. Dicho recurso no añade nada sustancial frente a las anteriores, pues todos ellos son jurídicos y a través de órganos independientes ${ }^{49}$.

Recordemos en especial lo que dispone el artículo 5.1 de la LOPJ con relación a la defensa de todos los derechos fundamentales por los jueces y tribunales. Por consiguiente, el respeto al derecho de sufragio activo y pasivo obliga enteramente a todos los que intervienen en esos controles previos y, muy particularmente, al Tribunal Supremo. $\mathrm{Si}$, a pesar de ello, se estima fundamental el recurso de amparo, no debe ser mucha la confianza que se mantiene en ese tribunal y en su cumplimiento de esa exigencia. Y eso sorprende tratándose de un órgano jurisdiccional definido por el artículo 123.1 de la Constitución como superior en todos los órdenes.

Pero si desde el punto de vista funcional se nos antoja innecesario y dilatador el recurso de amparo, desde otro formal advertimos reparos de pura inconstitucionalidad. Pues respecto a "la validez de las actas y credenciales de los miembros de ambas Cámaras" el único control previsto (art. 70.2 de la Constitución) es "el control judicial», expresión que se convendrá que no cubre al Tribunal Constitucional, entre otras razones porque el mismo no forma parte del poder judicial, según se desprende de su regulación separada en el título IX de la ley fundamental.

Son numerosos y notables los autores que han defendido justo lo contrario, a saber: que el recurso de amparo se desprende de las previsiones generales de la Constitución y que, por tanto, puede ser utilizado contra la sentencia del Tribunal Supremo al resolver un recurso contencioso electoral (lo mismo que contra las sentencias que resuelven los recursos contencioso administrativos sobre las candidaturas). Esta tesis es claramente la asumida por el propio Tribunal Constitucional, que desde el primer momento no ha sentido ningún reparo en conocer las acciones así ejercitadas ${ }^{50}$.

49 PULIDO QUeCEdo (1991-92, p. 1050) afirma en este sentido que «existen razones de fondo y de oportunidad que aconsejan descargar al Tribunal Constitucional del contencioso electoral en general y del contencioso de proclamación de candidaturas en particular». También se manifiestan crítico BASTIDA FREIJEDO (1986, p. 48).

50 Así, la STC 45/1983 admitió y concedió un amparo por no admisión de una candidatura, cuando estaba vigente el Decreto ley 20/1977, de normas electorales. La 
Se invoca al efecto el artículo 53.1 de la Constitución, que, al referirse a este recurso, lo hace respecto a varios derechos fundamentales y, entre ellos, claramente el de participación en los asuntos públicos del artículo 23.2. Por consiguiente, se dice, todo lo que afecte a ese derecho fundamental puede y deber ser conocido por el Tribunal Constitucional a través de esa vía. En el mismo sentido operaría el artículo 161.1.b, que reitera la aplicación de esta garantía a las posibles vulneraciones de toda una serie de libertades.

No discutimos que un acto administrativo o una resolución judicial puedan llegar a lesionar el derecho a participar en los asuntos públicos, como sería el caso de proclamar electo a un candidato con menos votos que otro o a uno que no cumpliese las condiciones de elegibilidad. Lo que discutimos es que el remedio frente a esa lesión venga dado por el recurso de amparo.

Para empezar el control de la validez de las elecciones es un elemento materialmente constitucional, esto es, dotado de una importancia indiscutible y por ello merecedor de aparecer en la ley fundamental. Las constituciones que antes hemos citado y las propias históricas españolas dan buena fe de ello. Consiguientemente, como tal elemento materialmente constitucional debe ser considerado en la forma con que aparece en la ley de leyes: lo no recogido no es algo que quede al albur del legislador ordinario, sino probablemente algo que no fue querido por el constituyente y que, por tanto, debe entenderse excluido.

Nuestra Constitución —en general detallada y precisa- omite toda referencia al recurso de amparo en materia electoral y sólo admite el judicial. El constituyente reguló inequívocamente el control de actas y, pudiendo haberlo hecho en su modalidad a cargo del órgano de justicia constitucional (como en Francia y parcialmente en Alemania), no sólo no lo hizo, sino que configuró uno distinto, el judicial ${ }^{51}$. A la luz de lo anterior, ha de concluirse que esa no mención del primero debe significar su exclusión, a menos que obren otras razones que no se nos antojan.

Por otro lado, como el elemento sistemático debe tenerse en cuenta en toda labor interpretativa, resulta que el artículo 70.2 de la Constitución actúa como una norma especial frente a las generales de los artículos 53.1y 161.1.b. Por ello su aplicación es preferente y excluye la de

STC 75/1985 controló la proclamación de electos al Parlamento de Cataluña, también al amparo de dicho decreto ley. Considerable repercusión en la posterior reforma de la LOREG tuvieron las STC 24/1990 y 131/1990.

51 Esto es reconocido por RALLo LOMBARTE (1997, p. 107), autor que sin embargo se muestra decidido partidario del recurso de amparo. 
estos últimos. Si no existiese aquel artículo, nada podría oponerse a la tesis que denunciamos. Pero como no es así, resulta que no puede ignorarse lo que implica su existencia. Adviértase que cuando la Constitución quiso compatibilizar dos controles o intervenciones así lo hizo, con cláusulas de "sin perjuicio" o "salvo lo dispuesto", como por ejemplo figuran en los artículos 82.6, 123.1 y 124.1. Como tampoco aparece esta cláusula en el caso de las elecciones, lo más sensato es pensar que sólo se quiso un control.

Además, este elemento sistemático coincide con el lógico, pues según reconocen las propias sentencias del Tribunal Constitucional el proceso electoral tiene unas condiciones muy especiales, como la perentoriedad de los plazos. En cuanto afecta a la composición del Parlamento, y no sólo a los intereses y derechos de los candidatos, es enteramente lógico que el control sea más expeditivo que el que referente a una cuestión sin estas connotaciones. Y esto, por reducción al absurdo, debe llevar a la consideración de que el constituyente no quiso desembocar en una situación reñida con esta exigencia. ¿Pudo querer el constituyente el doble control a sabiendas de que ello puede retrasar considerablemente la definitiva adjudicación de escaños? Lo lógico es pensar que no.

Confirman nuestra impresión la LOTC y la versión original de la LOREG. La primera de estas dos leyes regula con detenimiento las cuestiones de su competencia y los procedimientos al efecto. Pues bien, ni por un momento ordena o se refiere a un recurso de amparo contra actos de la Administración electoral o contra la proclamación de candidatos y electos. De ser cierto que el recurso de amparo electoral estaba embebido en las normas generales de la Constitución, lógicamente tenía que haberse reflejado en la LOTC. Obsérvese, en efecto, que esta ley contiene previsiones específicas para los actos y omisiones de órganos legislativos (art. 42), ejecutivos (art. 43) y judiciales (art. 44). Así las cosas, ¿no resultaba congruente demandar una previsión paralela para los actos de la Administración electoral, tanto por ser una organización atípica, no incluible entre las anteriores, como por la trascendencia de sus funciones? El silencio que reina en este punto es bien expresivo, a nuestro juicio, de que tampoco quiso el autor de la LOTC incluir esta nueva competencia y que, al contrario, aceptó tácitamente que el control electoral no pasase del previsto en el artículo 70.2 de la Constitución.

Se objetará a lo anterior que el artículo 41.2 de la misma ley emplea un lenguaje genérico al contemplar el objeto del recurso de amparo - «actos jurídicos o simple vía de hecho de los poderes públicos del Es- 
tado, Comunidades Autónomas y demás entes públicos de carácter territorial ...»- expresión que cubriría a los procedentes de las juntas electorales, dada su condición de poder público. Mas, aunque es cierto esto último, no lo es menos que dicho artículo no aparece contrapuesto a los siguientes, sino que actúa como una suerte de preámbulo de los mismos. El significado de dicho artículo se concreta en los siguientes, a donde habrá de acudirse para comprobar si los actos de una organización tan especial como son las juntas electorales están o no sujetos al recurso de amparo. Como no existe tal previsión, según correspondería a la importancia de las mismas, hay que concluir que la LOTC tampoco quiso que el recurso de amparo se extendiese a los actos de la Administración electoral ${ }^{52}$. Constituye una manifestación más de la fiebre formalista que nos inunda el interpretar aisladamente y en su pura literalidad el citado artículo 41.2.

Se nos objetará también que, al amparo del artículo 44 de la LOTC, las sentencias de los Juzgados de lo contencioso administrativo sobre las candidaturas y las del Tribunal Supremo en el procedimiento contencioso electoral, son susceptibles de ser impugnadas en vía de amparo constitucional. Pero, haciendo abstracción de que dicho artículo sólo admite ese recurso contra vicios procesales y no contra posibles incidencias en otros derechos fundamentales, tal argumentación quebraría por el mismo lugar que las anteriores, a saber, su literalidad, el aplicar una regla general al margen de una norma específica para un caso muy concreto, norma que además es de rango constitucional.

Finalmente, corrobora nuestra impresión el hecho de que la LOREG de 1985 nació sin contemplar el recurso de amparo electoral. En efecto, su primitivo artículo 114 disponía: «1. La Sentencia se notifica a los interesados no más tarde del día trigésimo séptimo posterior a las elecciones. 2. Contra la misma no procede recurso contencioso alguno, ordinario ni extraordinario, salvo el de aclaración". Consiguientemente, si la ley más directamente relacionada con el proceso electoral omitía toda referencia a dicho recurso es, sin duda, por que no se le consideró compatible con las previsiones constitucionales.

Fue la modificación de la LOREG por la Ley orgánica 8/1991 la que introdujo el recurso de amparo electoral. Dicha reforma, a nuestro juicio, obedeció, más que a razones teóricas, a la necesidad de reflejar lo que, por otro lado, era una realidad innegable. $Y$ es que el Tribunal Constitucional había admitido desde fecha muy temprana recursos de

${ }^{52} \mathrm{Al}$ menos respecto a los actos directamente involucrados en el proceso electoral. Otra cosa podría defenderse respecto de los que quedan al margen del mismo, como es cuando actúan como Administración en sentido estricto. 
amparo, tanto contra la proclamación de candidaturas como contra la proclamación de electos ${ }^{53}$, haciendo de esto último algo que no debía quedar al margen de la ley. La reforma no hizo más que consolidar lo que ya existía en la práctica.

Esa interpretación del órgano de justicia constitucional y la innovación legislativa recién mencionada podrían ser hechas valer en contra de nuestra postura. En especial la última, pues aparentemente podría quedar fundamentada en la cláusula ampliatoria de competencias del artículo 161.1.d de la ley fundamental. Sin embargo, no por eso deja de chocar con las consideraciones ya advertidas, que se derivan del artículo 70.2. Una ampliación de competencias es factible en la medida que no se contravenga un mandato constitucional, como el representado por ese artículo. Por su parte, la jurisprudencia del Tribunal Constitucional — verdadero detonante de la reforma - es criticable por las mismas razones. El compulsivo deseo de dicho tribunal de protagonizar hasta el último resquicio de lo que, directa o indirectamente, pueda incidir en los derechos fundamentales ha conducido a esa expansión del recurso de amparo hasta un terreno que le estaba vedado por el artículo 70.2 de la Constitución. El resultado es así la declaración tácita de la insuficiencia de la garantía representada por ese artículo.

\section{CONCLUSIONES}

Tras todo lo anterior, procede extraer conclusiones. En este sentido no parece exagerado afirmar que existe algo de exceso y algo de defecto en nuestros interregnos parlamentarios. Estas situaciones reclaman para su enderezamiento una reforma, bien de la Constitución, bien de la LOREG.

A continuación nos referiremos a los aspectos que atañen a la Constitución y luego se hará lo mismo respecto a la LOREG.

\section{Conclusiones respecto a la Constitución}

Nuestra Constitución es defectuosa por cuanto falta presencia parlamentaria entre el término de una legislatura y el comienzo de la siguiente. No sólo el paréntesis es muy amplio, sobre todo si se tiene en cuenta

53 Así, la STC 45/1983 admitió y concedió un amparo por denegación de una candidatura al amparo del anterior Decreto ley de normas electorales de 1977. La STC 75/1985 controló la proclamación de electos al Parlamento de Cataluña, también al amparo de dicho Decreto ley. Considerable repercusión tuvieron las STC 24/1990 y $131 / 1990$. 
los medios disponibles y lo observado en otros países, sino que el remedio de las Diputaciones permanentes es claramente insuficiente: sus funciones son demasiado restringidas y dejan al margen toda una serie de cuestiones cuya vigilancia y debate pueden resultar inaplazables.

A nuestro juicio, sería recomendable imitar en este punto las fórmulas de otros países expuestas en el epígrafe 8, de tal modo que, por un lado, para el supuesto deseable de agotamiento de la legislatura, se dispusiese que las elecciones se celebren dentro de los tres meses anteriores a ese momento, con la consecuencia de que los nuevos Congreso y Senado pudiesen constituirse sin solución de continuidad con los anteriores. Esto permitiría que las cámaras (pleno y comisiones) continuasen ejerciendo sus funciones regulares durante el período preelectoral, satisfaciendo así cualquier exigencia que se plantease.

Sin duda, ese período preelectoral puede hacer inconveniente el mantenimiento tal cual de la actividad parlamentaria. Será la prudencia política la que marque entonces el límite entre lo que no puede aguardar para su debate a la siguiente legislatura y lo que sí puede. En todo caso, la mayoría conserva siempre la llave de la aprobación del orden del día, por lo que cabe presumir que no serán muchos los excesos que se cometan. Y, como siempre, la opinión pública será el juez supremo de lo que acontece en el Parlamento.

Lo que debe desaparecer es la "coartada" de lo prohibido por la Constitución. La Constitución no puede propiciar que el ejecutivo quede inmune a toda fiscalización durante un plazo tan dilatado, pues ello sería un apartamiento de sus principios.

Para el caso de disolución anticipada, debería establecerse que los poderes de la cámara o cámaras disueltas quedarían prorrogados hasta la reunión de las nuevas ${ }^{54}$. De este modo, se obtendrían los mismos efectos que en el caso anterior.

Apenas es necesario decir que las fórmulas anteriores excluirían las Diputaciones permanentes, con lo que de paso se conseguiría una organización más simple y comprensible para la mayoría.

$Y$ menos necesario es expresar que todo lo anterior implica una reforma de los artículos 68.6 y 78 de la Constitución.

\section{Conclusiones respecto a la LOREG}

La LOREG adolece de uno de los males más extendidos en nuestra vida jurídica (legislación y jurisprudencia), como es el exceso de for-

${ }^{54}$ En el mismo sentido se decanta CaAmaño. Véase, 1991, p. 286. 
malismo. Este formalismo se traduce en una inflación de garantías, que como toda inflación devalúa aquello a que afecta. Así, las garantías se quedan no pocas veces en oropeles vacíos, incapaces de aportar algo efectivo. Al haberse buscado más su cantidad que su calidad, el resultado es que se cumplen atropelladamente, como trámites obligados, sin las condiciones apropiadas para satisfacer su fin teórico, dejando no pocas veces al presunto destinatario sin un beneficio tangible. $\mathrm{O}$, cuando aportan un remedio, resulta que el mismo llega con un retraso que hace inútil el mismo.

De otra parte, estas extravagancias formales son expresión de una cruda actitud individualista. Aunque se revisten normalmente de un ropaje hiperdemocrático, esto no es más que un disfraz que apunta a un planteamiento no precisamente solidario o comunitario. Se ignoran las exigencias colectivas, las que demanda el sistema político democrático, sin el cual la vigencia de las libertades individuales acaba siendo letra muerta. Pues, junto a los valores individuales también están los colectivos, ambos interdependientes, hasta el punto de que algunas veces los primeros pueden y deben ceder ante los segundos, como sería el caso típico de la expropiación. En otro caso, el entramado institucional y la propia vida democrática se ven sujetos a gravámenes que amenazan su funcionamiento.

Según se ha visto, la LOREG, en su redacción actual, es exponente de esta actitud. Se pretenden proteger los derechos de los electores y candidatos individuales con diversos controles y recursos. Pero, se hace de modo tan acentuado, que al final se acaba pagando un enorme precio con una de las piezas capitales del sistema democrático, como es el Parlamento, por cuanto todos esos formalismos se traducen en un serio retraso en su funcionamiento. Además, el sistema acaba negándose a sí mismo, por cuanto al superponer tantos controles y garantías parece como si se desconfiase de los dispuestos en primer lugar. Otras veces la protección de unos pocos repercute negativamente en los más ${ }^{55}$.

${ }_{55}$ Así, la irrestricta libertad para presentar candidaturas electorales, sin exigir fianza o caución, como en cambio ocurre en la mayoría de las democracias consolidadas, determina que se multipliquen las candidaturas - llamémoslas para no recargar la expresión- pintorescas, sin posibilidad de obtener un siquiera mínimo número de votos, causando unos cuantiosos gastos (como la confección y distribución de papeletas de voto, espacios gratuitos de propaganda en la televisión pública) y unas no menores complicaciones (como la papeleta de votación para el Senado en muchas provincias). Todo ello es el conjunto de ciudadanos el que lo acaba pagando y soportando. 
Por eso, y como resumen de lo expuesto en este artículo, procede referir las reformas que merece la LOREG.

En primer lugar, creemos que el control de regularidad de las candidaturas debe concluir con la reclamación ante las juntas electorales provinciales y, en su caso, con el recurso ante la Junta Electoral Central. A cambio, deben desaparecer el recurso contencioso administrativo y, sobre todo, el recurso de amparo ante el Tribunal Constitucional.

Si se estimase que la Administración electoral no ofrece garantías suficientes para asumir en exclusiva esta función controladora, podría procederse a su judicialización integral, siguiendo el modelo italiano, en el sentido de que todos sus miembros estarían extraídos de la carrera judicial. De este modo, no se podría objetar la falta de independencia de esta organización.

Una excepción a la ausencia de recurso contencioso administrativo podría admitirse, por su peculiaridad y gravedad, en los casos contemplados en los artículos 44.4 y 49.5 de la LOREG (prohibición de presentar candidaturas a agrupaciones de electores relacionadas con partidos políticos disueltos o suspendidos), con la consiguiente acción ante la Sala especial del artículo 61 de la LOPJ.

Respecto a la campaña oficial, o periodo de propaganda electoral, cabe proponer varias medidas. Una primera sería su acortamiento a siete días, para así reducir también toda la duración del proceso electoral. Es más, con el mismo propósito, podría iniciarse antes esta campaña, concretamente tras la proclamación oficial de las candidaturas. Alternativamente, podría suprimirse toda referencia a este periodo, en la inteligencia de que la propaganda electoral comienza ( ¿o tal vez continúa?) con la convocatoria de las elecciones, por lo que se ofrece plazo suficiente para que las candidaturas transmitan al electorado sus programas y propuestas. A lo sumo podría preverse un plazo específico para algo, por otra parte cuestionable, como son los espacios de propaganda gratuita en la radio y televisión públicas.

Respecto al control sobre la validez de las elecciones y proclamación de electos, entendemos que debería existir uno solo en vía administrativa, bien por la junta electoral provincial respectiva, bien por la Junta Electoral Central. A cambio, el órgano competente debía disponer de un plazo algo mayor que el actual, casi testimonial, de veinticuatro horas. Debe mantenerse el segundo control, el operado por la jurisdicción contenciosa administrativa, y no sólo por ser consecuencia del artículo 70.2 de la Constitución, sino porque ofrece una garantía de examen imparcial de las posibles causas invalidantes de una elección. En 
cambio, resulta enteramente desaconsejable el recurso de amparo ante el Tribunal Constitucional: se trata de una garantía que choca con el recto sentido del artículo mencionado y que dilata innecesariamente una cuestión que conviene cerrar cuanto antes, como es la titularidad de los escaños. Si, eventualmente, se considerase indispensable que esta garantía se arbitrase por el órgano de justicia constitucional, como de hecho ocurre en algunos países, habría que reformar dicho artículo, sustituyendo la expresión "control judicial» por la de "control por el Tribunal Constitucional» o fórmula equivalente, como también consta en las constituciones de esos países. Pero, por las razones reiteradas, lo que debe descartarse es que este segundo se acumule al actualmente previsto. O uno u otro, pero no los dos.

\section{BIBLIOGRAFÍA}

Adda, Joëlle, Couvert-Castera, Olivier y Dufresnoy, Philippe, Code électoral commenté, Berger-Levraut, París, 1995

AlzagA, Oscar, Comentario sistemático a la Constitución española de 1978, Ediciones del Foro, Madrid, 1978.

Alonso de Antonio, Angel Luis, La diputación permanente de las Cortes en la historia constitucional española, Congreso de los Diputados, Madrid, 1991.

Alonso de Antonio, Angel Luis, La Diputación Permanente en la Constitución española de 1978, Universidad Complutense, Madrid, 1992.

Álvarez Conde, Enrique, "El gobierno en funciones» en Documentación administrativa núm. 246-247, 1996-97.

Arnaldo Alcubilla, Enrique, "Discontinuidad y permanencia de las Cámaras", en Los Parlamentos de Europa y el Parlamento Europeo, Madrid, 1997.

Arnaldo Alcubilla, Enrique, "Las juntas electorales: naturaleza y competencias" en IV jornadas de Derecho parlamentario Reflexiones sobre el régimen electoral, Congreso de los Diputados, Madrid, 1997.

Arnaldo Alcubilla, Enrique, El carácter dinámico del régimen electoral español, CEPC, Madrid, 2002.

Arnaldo Alcubilla, Enrique y Delgado-Iribarren, Manuel, Código electoral, El Consultor de los Ayuntamientos y de los Juzgados, La LeyActualidad, Madrid, 2003. 
BASSOLS COMA, Martín, "El sistema electoral español: balance y perspectivas" en Parlamento y sistema electoral, VI jornadas de la asociación española de letrados de parlamentos, Aranzadi, 1999.

BAyón Chacón, Gaspar, La disolución del Parlamento y otros estudios, Congreso de los Diputados, Madrid, 1999.

BAR Cendón, Antonio, La disolución de las cámaras legislativas en el ordenamiento constitucional español, Congreso de los Diputados, 1989.

BASTIDA FrEIJEDo, Francisco, "Ley electoral y garantías judiciales", en Revista de las Cortes Generales n. ${ }^{\circ}$ 7, 1986.

BOETTCHER, Enno y HÖGNER, Reinhard, Bundeswahlgesetz Bundeswahlordnung Handkommentar, 1994.

CaAmaño, Francisco, El mandato parlamentario, Congreso de los Diputados, Madrid, 1991.

Cazorla Prieto, Luis María, Comentarios a la Ley orgánica del régimen electoral general, Civitas, Madrid, 1986.

Cierco SieIRA, César, "La inconstitucionalidad de la exclusión del recurso judicial contra los acuerdos de las juntas electorales dictados en vía de alzada", Revista Española de Derecho administrativo, n. ${ }^{\circ} 109$, 2001.

Electoral Commission, The, Parliamentary elections, Factsheet M7, revised February 2003.

ENTRENA CUeSTA, Ramón, "El recurso contencioso-electoral» en IV jornadas de Derecho parlamentario Reflexiones sobre el régimen electoral, Congreso de los Diputados, Madrid, 1997.

Fernández-CARnicero, Claro J., Comentarios a la ley del gobierno, INAP, Madrid, 2002.

FERnÁNDEZ DomíngueZ, Arturo, Leyes electorales españolas de diputados a cortes en el siglo XIX, estudio histórico y jurídico-político, Civitas, Madrid, 1992.

Fernández Segado, Francisco, "Los recursos contra la proclamación de candidaturas y candidatos en la Ley Orgánica 5/1985 del Régimen Electoral General», en Poder judicial, n. ${ }^{\circ}$ 31, 1993.

Fernández Segado, Francisco, «El recurso contencioso-electoral» en Revista de las Cortes Generales n. ${ }^{\circ}$ 33, 1994.

Fernández Segado, Francisco "La disolución de las cámaras" en Comentarios a la Constitución española de 1978, IX, dirección O. Alzaga, Edersa, 1998. 
Figueruelo BurRieZA, Angela, "Notas acerca del recurso de amparo electoral», Revista española de derecho constitucional, n. ${ }^{\circ} 25,1989$.

Figueruelo Burrieza, Angela, "Los recursos constitucionales del procedimiento electoral», en Revista de las Cortes Generales, n. ${ }^{\circ} 24,1991$.

Fraile Clivillés, Manuel María, La Comisión Permanente de las Cortes, Editora Nacional, Madrid, 1974.

GÁlVez MuÑoz, Luis, "La independencia de la junta electoral central y sus garantías" en Parlamento y sistema electoral, VI jornadas de la asociación española de letrados de parlamentos, Aranzadi, 1999.

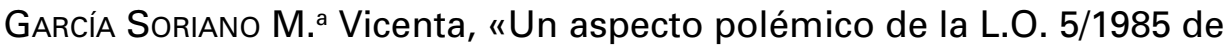
Régimen Electoral General : el veto al acceso a los tribunales de justicia", Cuadernos constitucionales de la Cátedra Fadrique Furió Ceriol, n. ${ }^{\circ} 17$ (Otoño 1996).

García Soriano, María Vicenta, "Problemas planteados por la exclusión del control judicial de algunos actos de la Administración electoral : el artículo 21 de la Ley Orgánica 5/1985", Revista general de derecho, n. ${ }^{\circ} 636$, sept. 1997.

García Soriano, María Vicenta, «El Consejo Constitucional y el control jurisdiccional de las elecciones legislativas en la República Francesa: los problemas actuales", en Corts : anuario de derecho parlamentario n. ${ }^{\circ}$ 7, 1999.

García Soriano, María Vicenta, Jueces y magistrados en el proceso electoral, CEPC, Madrid, 2000.

GonZaLo, Manuel, "Los medios de comunicación en el proceso electoral» en IV jornadas de Derecho parlamentario Reflexiones sobre el régimen electoral, Congreso de los Diputados, Madrid, 1997.

Martines T., De Caro C., Lippolis V. y Moretti R., Diritto parlamentare, Maggioli Ed., Rímini 1992.

MASCLET, J. CL., Le droit des élections politiques, PUF, París, 1992.

MAY, Erskine, Treatise on the law, privilegies, proceedings and usage of Parliament, edits. Sir Donald Limon, W.R. McKay, Butterworths, London, 1997.

Mazzoni Honoratı, Maria Luisa, Lezioni di diritto parlamentare, Giappicheli Ed., Turín, 1999.

Mazzoni Honoratı, Maria Luisa, Diritto parlamentare, Giappicheli Ed., Turín, 2001. 
MorHOFF, Federico, Tratatto di diritto e procedura parlamentare, Giovanni Bardi Ed., Roma, 1948.

PARDo FALCón, Javier, "El contencioso electoral en la LOREG» en Parlamento y sistema electoral, VI jornadas de la asociación española de letrados de parlamentos, Aranzadi, 1999.

PÉREz Dobón, Juan José, "Les activités parlementaires après la dissolution de la chambre: la Deputation Permanente espagnole» en Informations constitutionnelles et parlementaires n. ${ }^{\circ} 137,1984$.

Pérez Serrano, Nicolás, Tratado de derecho político, Civitas, Madrid, 1976.

Pérez Tremps, Pablo, "Composición, organización y estatuto de los miembros del Gobierno: apostillas al Proyecto de Ley del Gobierno", Documentación Administrativa núm. 246-247, 1996-97.

Pulido QueCEdo, Manuel, "Tribunal Constitucional y contencioso electoral", La Ley 2, 1991.

Pulido QueCEDo, Manuel, El acceso a los cargos y funciones públicas, un estudio del artículo 23.2 de la Constitución, Civitas, Madrid, 1992.

Rallo Lombarte, Artemi, Garantías electorales y constitución, CEPC, Madrid, 1997.

ReCODER DE CASso, Emilio, estudio del articulo 78 en Comentarios de la Constitución española de 1978, dirección F. Garrido Falla, Civitas, Madrid, 2001.

ReVEngA, Manuel, La formación del gobierno en la constitución española de 1978, C.E.C., Madrid, 1988.

Santaolalla, Fernando, Derecho parlamentario español, Espasa, Madrid, 1990.

Santaolalla, Fernando, estudio del artículo 101 en Comentarios de la Constitución española de 1978, dirección F. Garrido Falla, Civitas, Madrid, 2001( ${ }^{\mathrm{a}}$.

SANTAOLALla, Fernando, estudio del artículo 115 en Comentarios de la Constitución española de 1978, dirección F. Garrido Falla, Civitas, Madrid, 2001.

Santolaya MachettI, Pablo, Manual de procedimiento electoral, Ministerio del Interior, Madrid, 1995.

SANTOLAYA MACHETTI, Pablo, "La crisis del procedimiento electoral» en Reflexiones sobre el régimen electoral, IV jornadas de derecho parlamentario, Congreso de los Diputados, Madrid, 1997. 
Serena Velloso, Cecilio, artículos 8 a 15 en Comentarios a la Ley orgánica del régimen electoral general, dir. Cazorla Prieto, Luis María, Civitas, Madrid, 1986.

SolozÁbal EcheVArRía, Juan José, "Una visión institucional del proceso electoral", en IV jornadas de Derecho parlamentario Reflexiones sobre el régimen electoral, Congreso de los Diputados, Madrid, 1997.

VinCENT, Jean Yves, y ViLliers, Michel, Code électoral, Litec, París, 1993.

WERT, José Ignacio, "Perspectivas de reforma del régimen electoral: campañas, medios de comunicación y encuestas electorales", en $\mathrm{La}$ reforma del régimen electoral, CEC, Madrid, 1994. 